\title{
Nitrogen-doped biochars as adsorbents for mitigation of heavy metals and organics from water: a review
}

\author{
Nitesh Kasera' ${ }^{1}$. Praveen Kolar $^{1} \cdot$ Steven G. Hall ${ }^{1}$
}

Received: 13 October 2021 / Accepted: 16 February 2022

(c) The Author(s) 2022

\begin{abstract}
Mitigation of toxic contaminants from wastewater is crucial to the safety and sustainability of the aquatic ecosystem and human health. There is a pressing need to find economical and efficient technologies for municipal, agricultural, aquacultural, and industrial wastewater treatment. Nitrogen-doped biochar, which is synthesized from waste biomass, is shown to exhibit good adsorptive performance towards harmful aqueous contaminants, including heavy metals and organic chemicals. Incorporating nitrogen into the biochar matrix changes the overall electronic structure of biochar, which favors the interaction of $\mathrm{N}$-doped biochar with contaminants. In this review, we start the discussion with the preparation techniques and raw materials used for the production of $\mathrm{N}$-doped biochar, along with its structural attributes. Next, the adsorption of heavy metals and organic pollutants on $\mathrm{N}$-doped biochars is systematically discussed. The adsorption mechanisms of contaminant removal by $\mathrm{N}$-doped biochar are also clearly explained. Further, mathematical analyses of adsorption, crucial to the quantification of adsorption, process design, and understanding of the mechanics of the process, are reviewed. Furthermore, the influence of environmental parameters on the adsorption process and the reusability of $\mathrm{N}$-doped biochars are critically evaluated. Finally, future research trends for the design and development of application-specific preparation of N-doped biochars for wastewater treatment are suggested.
\end{abstract}

Nitesh Kasera

nkasera@ncsu.edu

1 Department of Biological and Agricultural Engineering, North Carolina State University, Raleigh, NC, USA 


\section{Graphical abstract}

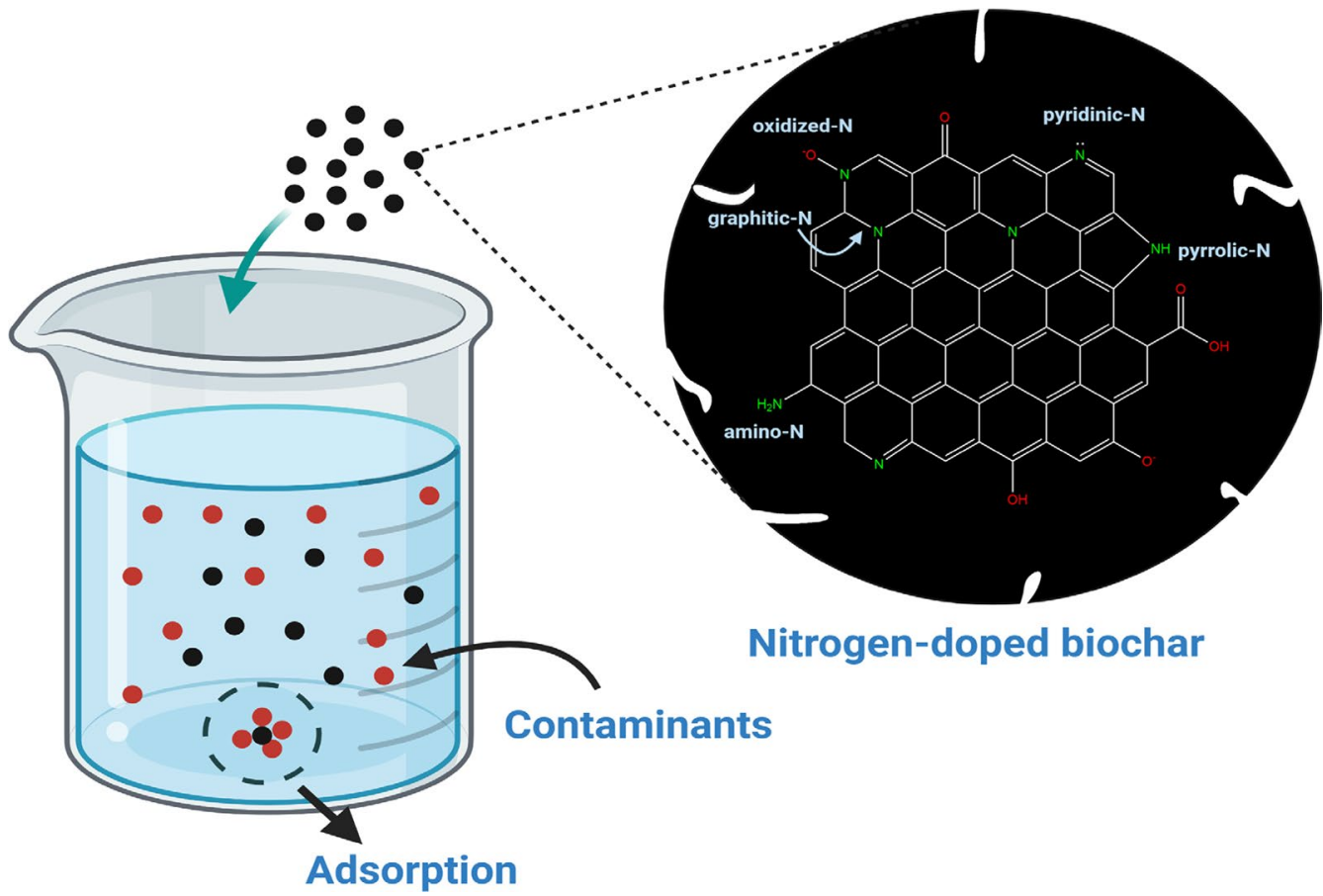

\section{Highlights}

- Recent research on adsorptive properties of nitrogendoped biochar are critically summarized.

- Adsorption and catalytic degradation of aqueous pollutants by nitrogen-doped biochars are discussed.

- Current knowledge gaps are identified, and recommendations for future research are proposed.

Keywords N-doped · Nitrogen-enriched · Adsorption · Wastewater $\cdot$ Mechanism

\section{Introduction}

Water is an absolute necessity for humans and other living organisms. However, the water quality of rivers, lakes, and other water bodies is deteriorating as harmful chemical substances are deposited due to human endeavors. Toxic chemicals, such as heavy metals and organics, have an adverse impact not only on aquatic living organisms but also on the broader biological community (Guo et al. 2015). Heavy metals such as lead $(\mathrm{Pb})$, copper $(\mathrm{Cu})$, zinc $(\mathrm{Zn})$, nickel $(\mathrm{Ni})$, cadmium $(\mathrm{Cd})$ are elements with densities above $5 \mathrm{~g} / \mathrm{cm}^{3}$ (Van Tran et al. 2018). Various industrial processes, metal-plating facilities, tanneries, and other human activities discharge heavy metals into the environment. When present above the tolerance levels, heavy metals can be detrimental to human health, causing cancer, anemia, hallucination, insomnia, and many other problems (Ali et al. 2011; Al-Abachi et al. 2013). Besides, certain heavy metals such as $\mathrm{Pb}$ and $\mathrm{Cd}$ are considered endocrine disruptors (Iavicoli et al. 2009). Similarly, organic chemicals such as dyeloaded wastewater discharged mostly from textile industries endanger environmental stability besides affecting aquatic life. Dyes are complex and stable compounds whose natural degradation is not quick and easy (Van Tran et al. 2018). Thus, dyes tend to accumulate in water bodies. Even so, over $10 \%$ of 1 million tons of industrially used dye are discharged as effluents into water bodies (Yagub et al. 2014). Although strict emission standards are imposed by governing organizations like the United States Environmental Protection Agency (Chemical oxygen demand of $163 \mathrm{~kg}$ per tonne of fabric), in reality, these values could be much higher. Thus, it is imperative to develop effective and economical water treatment technologies.

Various remediation technologies exist for pollutant removal from wastewater, including ion exchange, reverse osmosis, adsorption, precipitation, coagulation, electrodialysis, electrolysis, advanced oxidation processes, and biological methods (Singh et al. 2018; Zhu et al. 2016). These 
remediation techniques have exhibited various degrees of pollutant removal efficiencies. However, most of these processes, such as electrolysis, electrodialysis, reverse osmosis, ion exchange, and others, require a sophisticated setup and high energy demand, increasing the costs (Ali and Gupta 2007; Singh et al. 2018). Other chemical techniques such as coagulation and precipitation require the addition of chemicals, provide low removal efficiency, and create the burden of sludge treatment, and the biological methods are relatively slower (Singh et al. 2018). On the other hand, adsorption offers a practical and economical way of treating wastewater, which is simple to operate and does not involve any sophisticated process or instrument. In its simplest form, adsorption involves the attraction and immobilization of a given solute molecule (adsorbate) on the surface of a solid (adsorbent) via physical (Van der Waals) and chemical (bond sharing) interactions. From a process standpoint, the cost of adsorption varies from 10 to 200 US\$ per million liters for treated water, which is very low compared to $10-450$ US\$ per million liters cost incurred in reverse osmosis, ion exchange, and electrodialysis. Most importantly, adsorption can be applied widely to remove soluble, insoluble, and biological contaminants with a 90-99\% removal efficiency (Ali and Gupta 2007). Hence, there is a renewed interest in developing adsorption-based water treatment technologies to mitigate heavy metals, dyes, and other organic pollutants.

In the context of adsorption, biochar is an emerging eco-friendly adsorbent for wastewater treatment (Tan et al. 2015). Biochar is a product of pyrolysis of waste biomass. With the staggering progress in urbanization and industrialization, the inevitable generation of undesired biomass waste has exceeded its natural degradation capacity and requires financial cost for proper disposal (Wan et al. 2020a). Biochar preparation from waste materials could be a viable solution, as biochar has shown promising potential in several fields, including soil amendment (Chan et al. 2008; Schmidt et al. 2014), carbon storage (Fowles 2007), global warming mitigation (Woolf et al. 2010; Meyer et al. 2012), energy storage (Tan et al. 2017; Liu et al. 2019; Ehsani and Parsimehr 2020), and wastewater treatment (Xu et al. 2014; Li et al. 2017; Qambrani et al. 2017). As an adsorbent, biochar has essential properties such as large specific surface area, porous structure, and surface functional groups (Liu et al. 2015). The adsorption properties of biochars with various preparation and modification processes have been extensively reviewed previously (Premarathna et al. 2019; Wang et al. 2019a; Zhang et al. 2020a; Cheng et al. 2021). Raw or pristine biochar has limited specific surface area and surface functionality compared to commercial activated carbon because of the nonstoichiometric nature of the original biomass (Duan et al. 2018). Therefore, to enhance desirable properties in biochar, they must be modified appropriately. Several modifications of biochar, including acid, base, ozone, and other chemical treatments, have already been studied and reviewed elsewhere (Rajapaksha et al. 2016; Wang and Wang 2019).

In recent years, biochar modification via doping with nitrogen has attracted interest (Fig. 1). The introduction of heteroatoms such as nitrogen into the ordered $\mathrm{sp}^{2}$-hybridized graphite structure modifies the original $\pi$-electron network's electronic charges due to the difference in electronegativity. This creates localized imbalanced charged regions throughout the carbon structure, forming an electroactive state which can be exploited for various useful applications. For example, nitrogen doping ( $\mathrm{N}$-doping) has been shown to improve nanocarbon's catalytic properties, facilitate nanomaterial dispersion, and enhance the detection limit of sensors (Wan et al. 2020a). N-doping on the biochar surface enhances electron mobility and improves its hydrophobic characteristics. Although the mechanism of N-doping on biochar is still not very clear, nitrogen-doped (N-doped) biochar has shown promising potential in the fields of adsorption (Qin et al. 2016; Yang et al. 2017), advanced oxidation processes (Xie et al. 2020; Xu et al. 2020; Zaeni et al. 2020), oxygen electrocatalysis (Liu et al. 2014; Borghei et al. 2017), supercapacitors ( $\mathrm{Li}$ et al. 2012; Biswal et al. 2013), microbial fuel cells (Huggins et al. 2015; Yue et al. 2015; Zhong et al. 2019), biofuels and bio-based chemical production (Dreyer et al. 2017; Chen et al. 2018a). The role of nitrogen functional groups on biochar surfaces, recent advancements of biochar preparation, and potential applications of $\mathrm{N}$-doped biochars have been reviewed recently (Leng et al. 2019; Wan et al. 2020a).

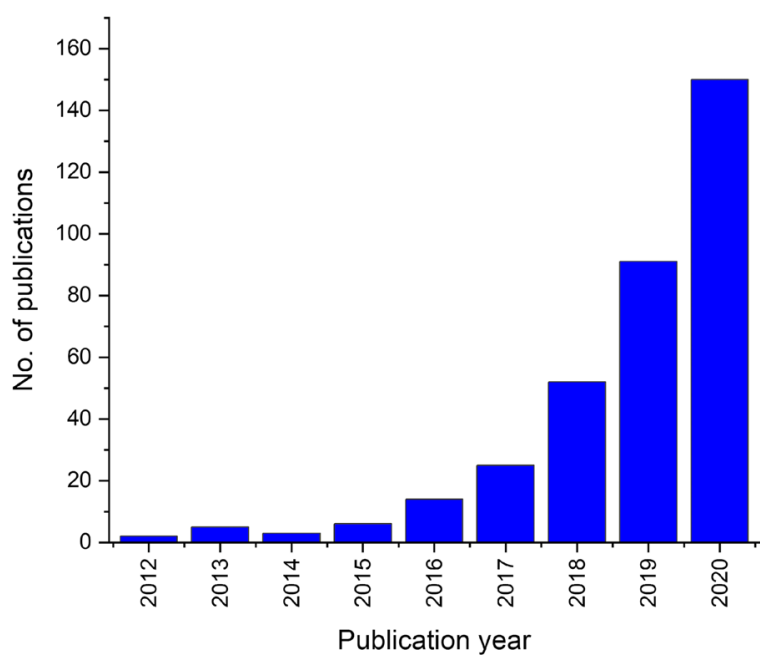

Fig. 1 Publication trend on N-doped biochars in recent years. The data was generated from the Web of Science database with search string "TS = ("Nitrogen doped biochar" OR "N-doped biochar" OR "Nitrogen modified biochar" OR "N-enriched biochar" OR "Nitrogen enriched biochar")" on February 10, 2021 
From a wastewater treatment perspective, N-doped biochar is being increasingly used as an adsorbent for the mitigation of several pollutants, including heavy metals (Chu et al. 2020) and organic compounds (Mian et al. 2019) from aqueous systems as well as acidic gases (Shao et al. 2018; Han et al. 2019). Nitrogen functional groups provide basicity to the biochar surface with diverse surface functionality. Together with these properties, nitrogen functional groups on biochar have been demonstrated to interact with the contaminants and immobilize them on the surface of the adsorbents through various chemical pathways (Lian et al. 2016; Yin et al. 2019). Previous reviews on $\mathrm{N}$-doped biochar discussed its preparation techniques, the effects of different preparation techniques on the N-doped biochar properties, and the overall environmental application fields of $\mathrm{N}$-doped biochar (Leng et al. 2019; Wan et al. 2020b; Li et al. 2020). Thus, considering $\mathrm{N}$-doped biochar's potential applications as an adsorbent in wastewater treatment, a review summarizing recent advancements in wastewater treatment via $\mathrm{N}$-doped biochars is warranted. No such review elucidating $\mathrm{N}$-doped biochars' adsorption characteristics is currently available. Therefore, in this review, we critically evaluate the adsorption performance of $\mathrm{N}$-doped biochars towards aqueous solutions of organic compounds and heavy metals based on recently published articles. The underlying mechanisms of contaminant interaction with $\mathrm{N}$-doped biochars have been discussed, along with the mathematical analyses of adsorption processes, the environmental factors affecting adsorption, and the recyclability of N-doped biochar. To make the reader understand the complete picture, we also included the various preparation routes and structural properties of N-doped biochar in our discussion. Finally, suggestions were made for the future advancement of the field based on the knowledge gaps.

\section{N-doped biochar synthesis}

Biomass is principally composed of cellulose, hemicellulose, and lignin. Thermal energy is applied to the biomass to rupture the bonds. As a result, a series of complex chemical reactions, such as dehydration, dehydrogenation, and cyclization, co-occur along with the removal of volatiles, resulting in a porous solid structure having amorphous regions (Liu et al. 2015). Depending on the nature of feedstock, i.e., the inherent nitrogen content of biomass, further heat treatment of biochar might be carried out in the presence of an $\mathrm{N}$-rich precursor to produce nitrogen modified (N-modified) biochar. In this section, the feedstocks for preparing $\mathrm{N}$-doped biochar along with its synthesis routes are discussed. The various routes of preparing $\mathrm{N}$-doped biochars are summarized in Fig. 2.

\subsection{Feedstock for preparing N-doped biochar}

$\mathrm{N}$-doped biochars can be synthesized by pyrolyzing either nitrogen-rich biomass or nitrogen-lean biomass supplemented with an external nitrogen source. Tables 1 and 2 outline different nitrogen-enriched biomasses and external nitrogen sources used for preparing N-rich biochar, respectively, along with the resulting biochars' characteristics. Many forms of waste biomass feedstock can be used for the synthesis of N-doped biochars. However, it is necessary to evaluate the doping efficiencies of these feedstocks to achieve optimum N-doping.

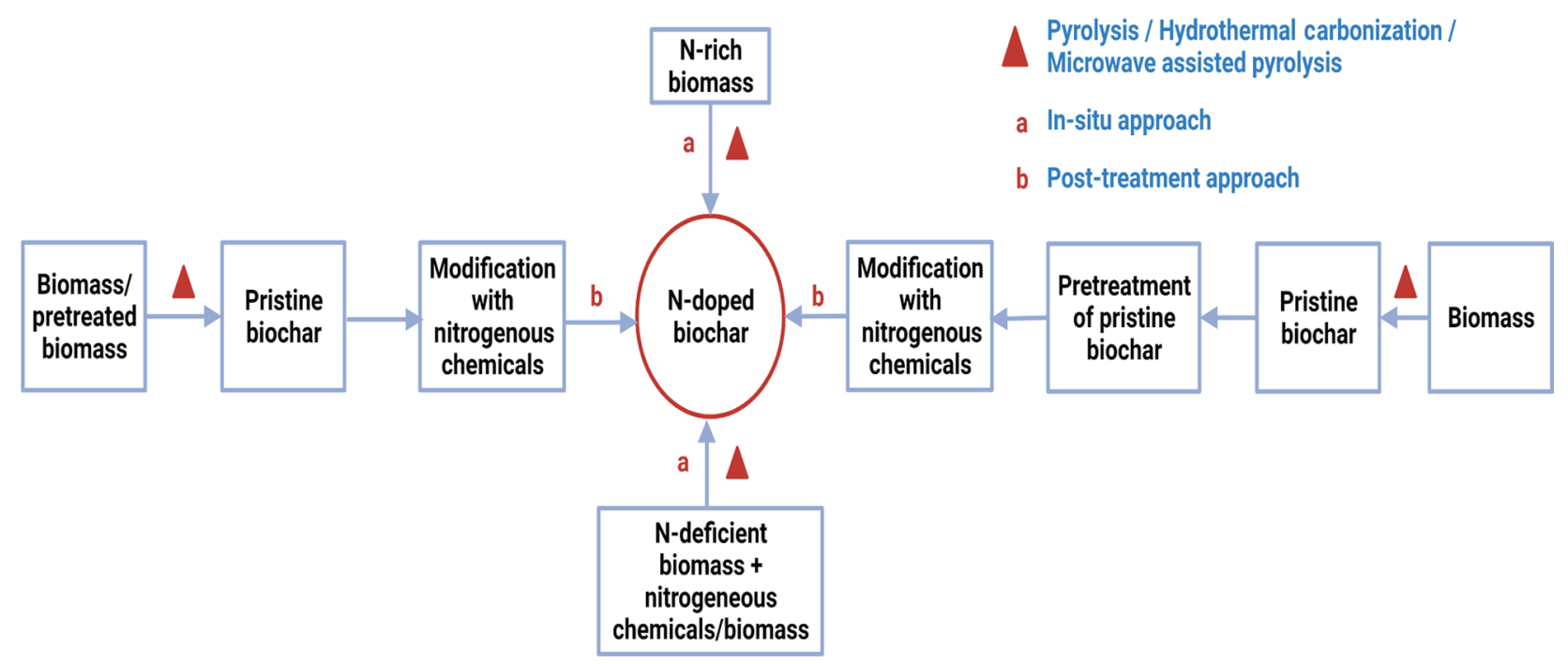

Fig. 2 Preparation techniques of N-doped biochars 
Table 1 Characteristics of N-doped biochars produced from nitrogen-rich biomass

\begin{tabular}{|c|c|c|c|c|c|}
\hline N-rich biomass & Processing conditions & $\mathrm{C} \% ; \mathrm{N} \%(\mathrm{wt} \%)$ & $\begin{array}{l}\text { Surface area }\left(\mathrm{m}^{2} / \mathrm{g}\right) \text {; pore } \\
\text { volume }\left(\mathrm{cm}^{3} / \mathrm{g}\right)\end{array}$ & $\mathrm{N}$-functional groups & Refs. \\
\hline Camellia sinesis & $\begin{array}{l}\text { Heated at } 120,160,200, \\
240 \text {, and } 280^{\circ} \mathrm{C} \text { for } 2 \mathrm{~h} \\
\text { under } 0.4,0.9,1.9,4.4, \\
\text { and } 6.5 \mathrm{MPa}\end{array}$ & $67.97 ; 5.36$ & $18.7 ; 0.080$ & $\begin{array}{l}\text { Pyridinic-N, pyrrolic-N, } \\
\text { graphitic-N }\end{array}$ & Ho et al. (2019) \\
\hline Iris sibirica $\mathrm{L}$. & $\begin{array}{l}\text { Pyrolysis temp: } 900{ }^{\circ} \mathrm{C} \text {; } \\
\text { Retention time: } 2 \mathrm{~h} \text {; } \\
\text { Atmosphere: } \mathrm{N}_{2} \text { gas }\end{array}$ & NA & NA & $\begin{array}{l}\text { Pyridinic-N, pyrrolic-N, } \\
\text { graphitic-N }\end{array}$ & Gao et al. (2016) \\
\hline Bean dreg & $\begin{array}{l}\text { Heated from room tem- } \\
\text { perature to } 800{ }^{\circ} \mathrm{C} \text { in } \\
30 \mathrm{~min} \text {; steam activated } \\
\text { for } 30 \mathrm{~min} \text {; Atmos- } \\
\text { phere: } \mathrm{N}_{2} \text { gas }\end{array}$ & $89.4 ; 2.42$ & $1004 ; 0.50$ & $\begin{array}{l}\text { Pyrrolic-N, pyridinic- } \\
\mathrm{N} \text {, graphitic-N, and } \\
\text { oxidized } \mathrm{N}\end{array}$ & Chu et al. (2020) \\
\hline Candida utilis & $\begin{array}{l}\text { Pyrolysis temp: } 700{ }^{\circ} \mathrm{C} \text {; } \\
\text { Heating rate: } 5^{\circ} \mathrm{C} / \mathrm{min} \text {; } \\
\text { Retention time: } 2 \mathrm{~h} \text {; } \\
\text { Atmosphere: Ar gas }\end{array}$ & $47.2 ; 4.66$ & 47.1 & $\begin{array}{l}\text { Pyrrolic-N, pyridinic-N, } \\
\text { graphitic-N }\end{array}$ & Guo et al. (2020) \\
\hline Human hair & $\begin{array}{l}\text { Pyrolysis temp: } 700,800 \text {, } \\
900^{\circ} \mathrm{C} \text {; Heating rate: } \\
2^{\circ} \mathrm{C} / \mathrm{min} \text {; } \\
\text { Retention time: } 1 \mathrm{~h} \text {; } \\
\text { Atmosphere: Ar gas }\end{array}$ & $85.28 ; 4.30$ & $3015 ; 1.51$ & Pyrrolic-N, graphitic-N & Liang et al. (2018) \\
\hline Banana peels & $\begin{array}{l}\text { Hydrothermally treated } \\
\text { at } 180^{\circ} \mathrm{C} \text { for } 6 \mathrm{~h} \text {; cal- } \\
\text { cined at } 600{ }^{\circ} \mathrm{C} \text { for } 2 \mathrm{~h} \\
\text { in } \mathrm{N} 2 \text { atmosphere }\end{array}$ & & $504 ; 0.5215$ & $\begin{array}{l}\text { Pyridinic-N, pyrrolic-N, } \\
\text { graphitic-N }\end{array}$ & Yuan et al. (2018b) \\
\hline Municipal sewage sludge & $\begin{array}{l}\text { Pyrolysis temp: } 400,600, \\
800^{\circ} \mathrm{C} \text {; Heating rate: } \\
5^{\circ} \mathrm{C} / \mathrm{min} \text {; Retention } \\
\text { time: } 2 \mathrm{~h} \text {; Atmosphere: } \\
\mathrm{N}_{2} \text { gas }\end{array}$ & $33.38 ; 2.46^{\mathrm{a}}$ & $\begin{array}{r}39.077-67.387 \\
0.0676-0.0884\end{array}$ & $\begin{array}{l}\text { Pyridinic-N, pyrrolic-N, } \\
\text { graphitic-N }\end{array}$ & Zhao et al. (2017) \\
\hline Watermelon rind & $\begin{array}{l}\text { Pyrolysis temp: } 400- \\
700^{\circ} \mathrm{C} \text {; Heating rate: } \\
5^{\circ} \mathrm{C} / \mathrm{min} \text {; Retention } \\
\text { time: } 2 \mathrm{~h} \text {; Atmosphere: } \\
\mathrm{N}_{2} \text { gas }\end{array}$ & NA & NA & $\begin{array}{l}\text { Pyridinic-N, pyrrolic-N, } \\
\text { graphitic-N }\end{array}$ & Zhong et al. (2019) \\
\hline $\begin{array}{l}\text { C-phycocyanin extracted } \\
\text { Spirulina residue }\end{array}$ & $\begin{array}{l}\text { Pyrolysis temp: } 300- \\
700^{\circ} \mathrm{C} \text {; Heating rate: } \\
15^{\circ} \mathrm{C} / \mathrm{min} \text {; Retention } \\
\text { time: } 1.5 \mathrm{~h} \text {; Atmos- } \\
\text { phere: } \mathrm{N}_{2} \text { gas }\end{array}$ & $16.59 ; 0.77$ & 117.90, NA & $\begin{array}{l}\text { Pyrrolic-N, pyridinic- } \\
\mathrm{N} \text {, graphitic-N, and } \\
\text { oxidized } \mathrm{N}\end{array}$ & Ho et al. (2019) \\
\hline Water hyacinth & $\begin{array}{l}\text { Biomass mixed with } \\
\mathrm{ZnCl}_{2} ; \text { Pyrolysis temp: } \\
600-800^{\circ} \mathrm{C} \text {; Retention } \\
\text { time: } 1 \mathrm{~h} \text {; Atmosphere: } \\
\mathrm{N}_{2} \text { gas }\end{array}$ & $91.12 ; 5.47^{\mathrm{a}}$ & $829 ; 0.99$ & Pyridinic-N, graphitic-N & Liang et al. (2018) \\
\hline Chitosan & $\begin{array}{l}\text { Pyrolysis temp: } 800{ }^{\circ} \mathrm{C} \text {; } \\
\text { Retention time: } 6 \mathrm{~h} \text {; } \\
\text { Atmosphere: Ar gas }\end{array}$ & $61.0 ; 10.0$ & $1052 ; 0.1$ & $\begin{array}{l}\text { Pyrrolic-N, pyridinic-N, } \\
\text { graphitic-N }\end{array}$ & Yuan et al. (2018b) \\
\hline Green algae & $\begin{array}{l}\text { Pyrolysis temp: } 800{ }^{\circ} \mathrm{C} \text {; } \\
\text { Heating rate: } 5^{\circ} \mathrm{C} / \mathrm{min} \text {; } \\
\text { Retention time: } 2 \mathrm{~h} \text {; } \\
\text { Atmosphere: Ar gas }\end{array}$ & NA & $101 ; 0.54$ & $\begin{array}{l}\text { Pyrrolic-N, pyridinic-N, } \\
\text { graphitic-N }\end{array}$ & Zhao et al. (2017) \\
\hline T. angustifolia & $\begin{array}{l}\text { Pyrolysis temp: } \\
\text { 600-800 }{ }^{\circ} \mathrm{C} ; \text { Heating } \\
\text { rate: } 300-800{ }^{\circ} \mathrm{C} / \mathrm{s} ; \\
\text { Retention time: } 1-2 \mathrm{~s} \text {; } \\
\text { Atmosphere: } \mathrm{N} 2 \text { gas }\end{array}$ & NA & $83.24 ; 0.095$ & Pyrrolic-N, pyridinic- $\mathrm{N}$ & Ling et al. (2017) \\
\hline
\end{tabular}


Table 1 (continued)

\begin{tabular}{|c|c|c|c|c|c|}
\hline N-rich biomass & Processing conditions & $\mathrm{C} \% ; \mathrm{N} \%$ (wt\%) & $\begin{array}{l}\text { Surface area }\left(\mathrm{m}^{2} / \mathrm{g}\right) ; \text { pore } \\
\text { volume }\left(\mathrm{cm}^{3} / \mathrm{g}\right)\end{array}$ & $\mathrm{N}$-functional groups & Refs. \\
\hline U. prolifera & $\begin{array}{l}\text { Hydrothermally treated } \\
\text { at } 200{ }^{\circ} \mathrm{C} \text { for } 4 \mathrm{~h}\end{array}$ & $61.9 ; 2.6$ & $25.43 ; 0.121$ & NA & Lu et al. (2017) \\
\hline Human hair & $\begin{array}{l}\text { Pyrolysis temp: } \\
300-700{ }^{\circ} \mathrm{C} \text {; Heating } \\
\text { rate: } 10^{\circ} \mathrm{C} / \mathrm{min} \text {; } \\
\text { Retention time: } \\
0.5-2.5 \mathrm{~h} \text {; Atmosphere: } \\
\text { oxygen-limited }\end{array}$ & $68.38 ; 9.61^{\mathrm{a}}$ & $\begin{array}{l}2.533-50.40 ; 0.003- \\
0.044\end{array}$ & Pyridinic-N, pyrrolic-N & Gao et al. (2016) \\
\hline Enteromorpha prolifera & $\begin{array}{l}\text { Pyrolysis temp: } \\
300-700^{\circ} \mathrm{C} ; \text { Heating } \\
\text { rate: } 10^{\circ} \mathrm{C} / \mathrm{min} \text {; } \\
\text { Retention time: } \\
0.5-2.5 \mathrm{~h} \text {; Atmosphere: } \\
\text { oxygen limited }\end{array}$ & $63.05 ; 1.09^{\mathrm{a}}$ & $\begin{array}{l}18.33-211.87 ; 0.015- \\
0.082\end{array}$ & Pyridinic-N, pyrrolic-N & Gao et al. (2016) \\
\hline Shrimp shell & $\begin{array}{l}\text { Heated at } 400{ }^{\circ} \mathrm{C} \text { for } \\
2.0 \mathrm{~h} \text { with a heating } \\
\text { rate of } 5^{\circ} \mathrm{C} / \mathrm{min} \text { under } \\
\mathrm{N}_{2} \text { atmosphere; mixed } \\
\text { with } \mathrm{KOH} \text { at different } \\
\text { ratios and activated at } \\
700,800 \text { and } 850{ }^{\circ} \mathrm{C} \\
\text { for } 1 \mathrm{~h} \text { with a heating } \\
\text { rate of } 5^{\circ} \mathrm{C} / \text { min under } \\
\mathrm{N}_{2} \text { atmosphere }\end{array}$ & $91.30 ; 0.664$ & $3171 ; 1.934$ & NA & Qin et al. (2016) \\
\hline
\end{tabular}

$N A$ data not available

${ }^{\text {a Atomic } \% ~}$

\subsubsection{Nitrogen-rich biomass}

Careful biomass selection is crucial for producing in-situ $\mathrm{N}$-doped biochars from $\mathrm{N}$-rich biomass sources. Ideally, such nitrogen-rich biomass should have a fair amount of $\mathrm{N}$ content in its inherent macromolecular structure or overall chemical composition (Wan et al. 2020a). Biochars derived from nitrogen-rich biomass such as municipal and animal wastes, algae, or weeds are likely to have a high $\mathrm{N}$ content in their structure due to recalcitrant protein structures. Biochars from these biomasses contain heterocyclic $\mathrm{N}$ moieties, which could change the delocalized $\pi$-bonded and $\mathrm{p}$ electronic environment of the aromatic carbon matrix by regulating the electron charge density (Zhu et al. 2020a). The characteristics of $\mathrm{N}$-doped biochars produced from nitrogen-rich biomass are summarized in Table 1.

Chu et al. prepared $\mathrm{N}$-doped biochars using bean dregs, which are high in protein content, for the adsorptive removal of $\mathrm{Cr}(\mathrm{VI})$. Bean dregs were carbonized at $400{ }^{\circ} \mathrm{C}$, steam activated at $800^{\circ} \mathrm{C}$, and heated again at higher temperatures to obtain $\mathrm{N}$-doped biochar samples (Chu et al. 2020). The authors reported the presence of pyridinic-N $(0.74 \mathrm{wt} \%)$, pyrrolic-N $(0.18 \mathrm{wt} \%)$, graphitic $\mathrm{N}(1.11 \mathrm{wt} \%)$, and pyridine$\mathrm{N}$-oxide $(0.39 \mathrm{wt} \%)$ in the samples. Protein-rich biological substances were also used to dope nitrogen on the biochar surface. Ho et al. pyrolyzed C-phycocyanin extracted Spirulina residue at 400,700 , and $900{ }^{\circ} \mathrm{C}$ to prepare $\mathrm{N}$-doped biochars for peroxydisulfate oxidation. The authors reported pyrrolic-N, pyridinic- $\mathrm{N}$, graphitic- $\mathrm{N}$, and oxidized $\mathrm{N}$ formed on the biochar surface (Ho et al. 2019). They also reported an increase in the degree of graphitization with increasing pyrolysis temperature, which was involved in the catalyst activation. However, Xie et al. used N-rich yeast to produce biochar at $600{ }^{\circ} \mathrm{C}$ for peroxymonosulfate activation and reported that a high graphitization degree was not required for the catalytic performance of $\mathrm{N}$-doped biochar nanosheets (Xie et al. 2020). The authors used molten salts in the pyrolyzing process to help retain nitrogen on the sheets. Alternatively, Gao et al. used keratin and algal-based biomasses as precursors for the synthesis of N-doped biochars (Gao et al. 2016). Human hair (keratin) and Enteromorpha prolifera (commonly available marine microalgae formed due to eutrophication) were pyrolyzed at different temperatures and holding times to produce $\mathrm{N}$-doped biochars equipped with pyridinic-N and pyrrolic-N on the surface. Guo et al. also used hydrothermal carbonization to produce in-situ N-doped biochar from Camellia sinensis for heavy metal ions adsorption (Guo et al. 2020). In addition to macroalgae, aquatic weeds were also shown to successfully produce $\mathrm{N}$-doped biochars. Liang et al. utilized water hyacinth (a malignant 


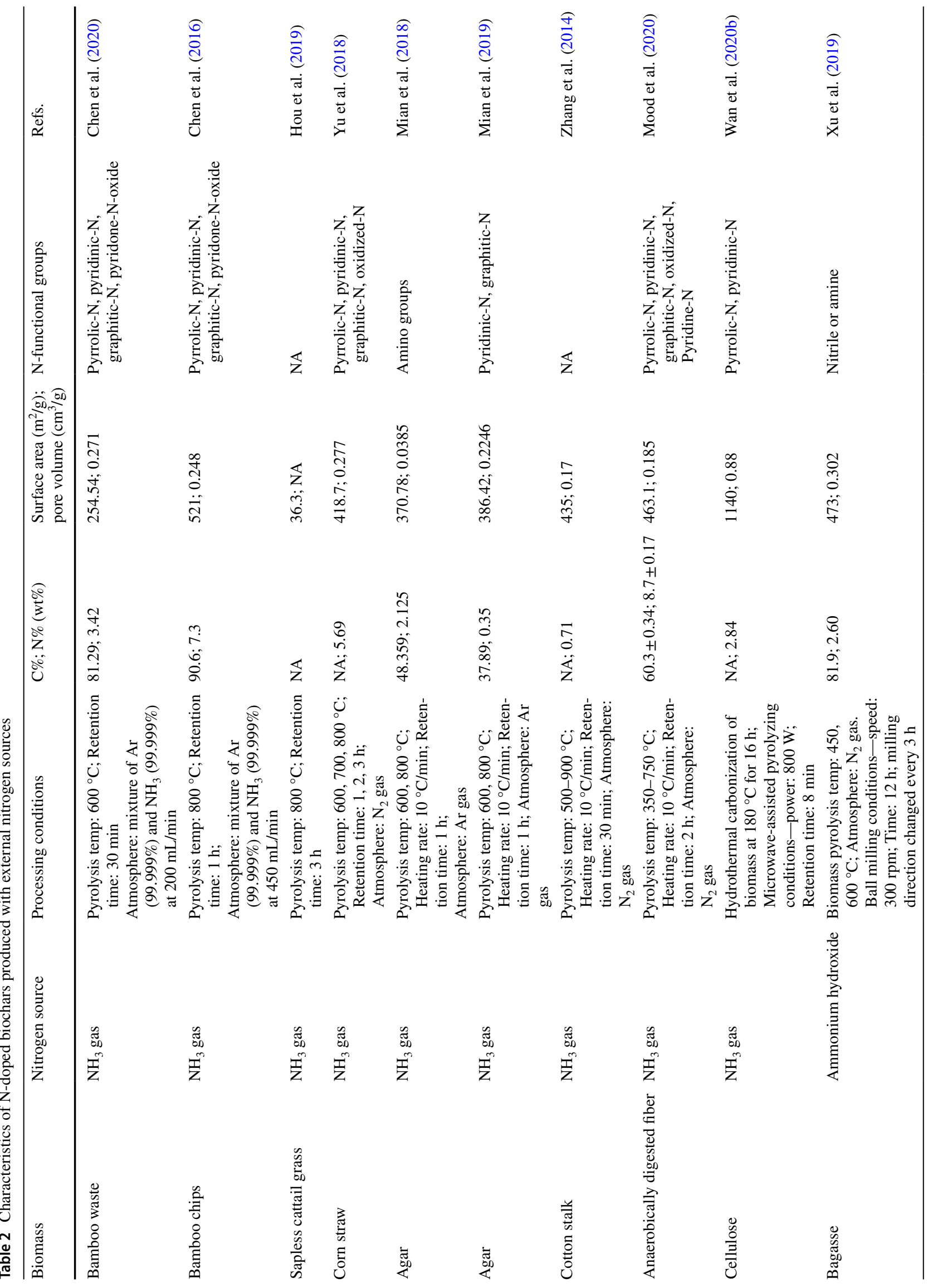




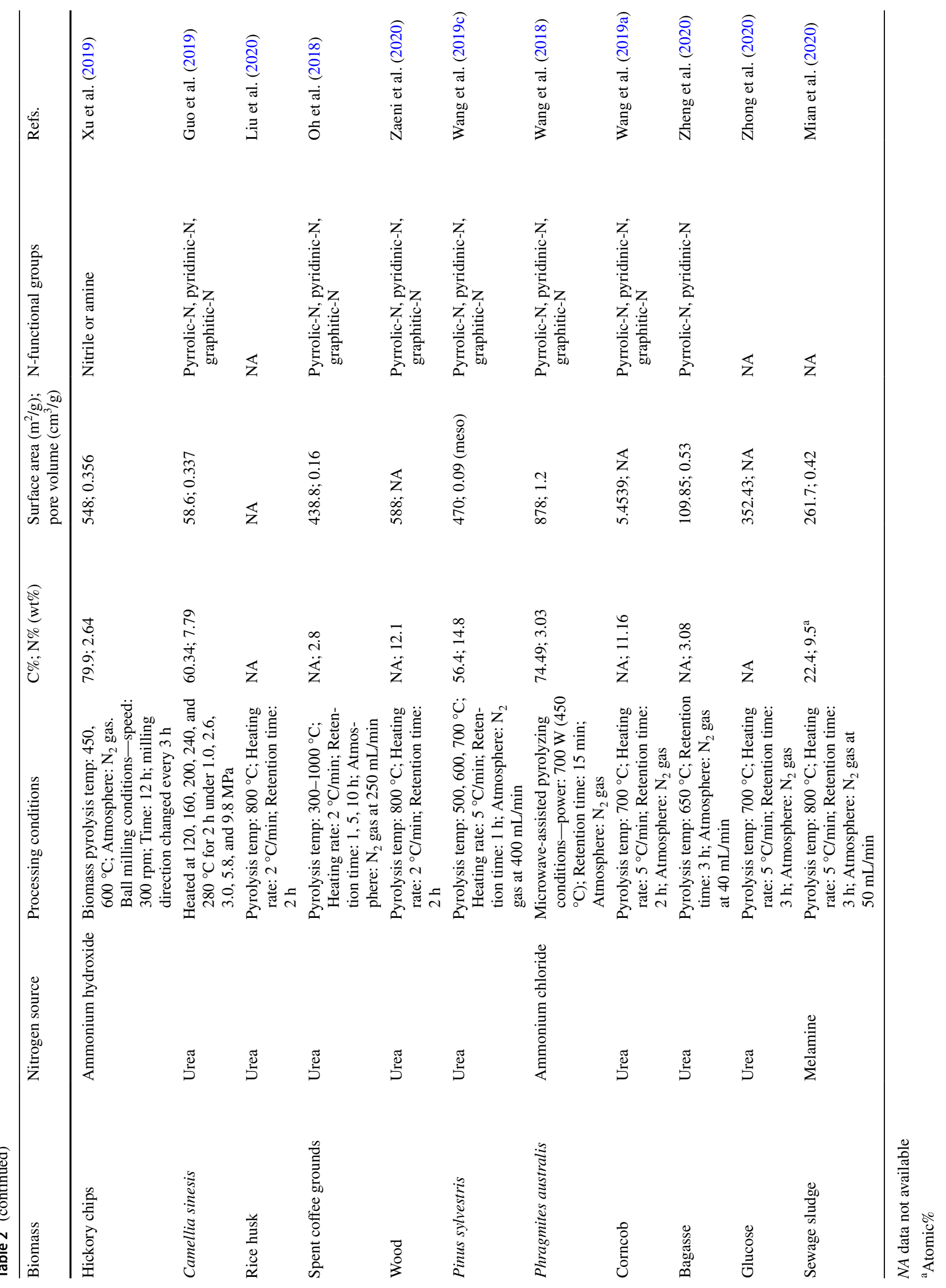


weed) to produce an $\mathrm{N}$-doped biochar cathode to degrade dimethyl phthalate (Liang et al. 2018). The prepared samples exhibited a high $\mathrm{N}$ content (7.71 atomic\%) and manifested excellent electrochemical performance due to the presence of pyridinic-N and graphitic-N. Yuan et al. used a sol-gel technique to prepare a series of high surface area $\mathrm{N}$-doped biochars with pyrrolic- $\mathrm{N}$, pyridinic-N, and graphitic-N using chitosan as a rich source of nitrogenous biomass to remove heavy metals (Yuan et al. 2018b). Based on the results, it is evident that nitrogen-rich biomass could be used as precursors to produce $\mathrm{N}$-doped biochars effectively. However, due to inherent heterogeneity in biomass, it seems challenging to precisely control the distribution of different individual nitrogen components in the produced biochars. Moreover, a comparative analysis on the retained $\%$ of native nitrogen in the resultant biochar from different $\mathrm{N}$-rich biomass could be beneficial to evaluate the optimum $\mathrm{N}$-doping efficiency in relation to feedstock. Thus, future studies are suggested regarding this aspect.

\subsubsection{External nitrogen resources}

For preparing $\mathrm{N}$-doped biochars with external nitrogen sources, different inorganic chemicals (e.g., ammonia gas, ammonium salts, and nitric acid), organic chemicals (e.g., urea, melamine), and nitrogenous biomass (e.g., shrimp bran, crab bran) have been used. For the biomass, e.g., wood, corncob, rice husk, which are nitrogen deficient, these nitrogenous chemicals serve as the nitrogen source necessary for doping onto the biochar. In contrast with $\mathrm{N}$-doped biochars produced from nitrogen-enriched biomass, the nitrogen content in the biochars produced with external nitrogen sources can be tuned by controlling the initial amount of the nitrogenous chemical used in the reaction. On the other hand, the molecular structure of these chemicals and their thermal behavior must be taken into consideration. Thus, the operational conditions for producing N-doped biochars from external nitrogen sources might need to meet stricter requirements. Depending on the biomass and nitrogen sources' structure and the operational conditions, the nitrogen concentration and bond configuration in the biochar may vary. The characteristics of $\mathrm{N}$-doped biochars produced with external nitrogen sources are summarized in Table 2.

Ammonia purging has been used previously to incorporate $\mathrm{N}$-functional groups in biochar. In addition, ammonium salts have also been employed to synthesize $\mathrm{N}$-doped biochar. Different ammonia salts have been reported, e.g., ammonium chloride (Wang et al. 2018), ammonium hydroxide (Xu et al. 2019), ammonium phosphate (Jin et al. 2020), ammonium nitrate (Kasera et al. 2021), and others have been used to synthesize $\mathrm{N}$-doped biochar. These salts decompose to form $\mathrm{NH}_{3}$ during pyrolysis. Thus, it can be assumed that these salts undergo similar transformations as $\mathrm{NH}_{3}$ purging (reacting with oxygen functionalities) to produce various $\mathrm{N}$-dopants on the biochar surface (Wan et al. 2020a). Zhu et al. (2018) fabricated N-doped biochars with a high graphitic- $\mathrm{N}$ content (61.7 atomic\% of total $\mathrm{N}$ content) using wetland plant (reed) and ammonium nitrate. The release of $\mathrm{NH}_{3}$ during pyrolysis with ammonium salts might also favor the formation of microporous channels in the obtained biochar.

Organic nitrogen additives have also been used in the $\mathrm{N}$-doping process. Oh et al. prepared $\mathrm{N}$-doped biochars with spent coffee grounds and urea at various pyrolyzing temperatures and holding times (Oh et al. 2018). The obtained $\mathrm{N}$-doped biochars had pyrrolic-N, pyridinic-N, and graphitic-N. With an increase in the temperature, the graphitic-N content increased while the pyrrolic-N and pyridinic-N content decreased, implying that at higher temperatures, pyridinic- $\mathrm{N}$ and pyrrolic-N might have transformed to graphitic-N. The N-doped biochars prepared by urea activation are associated with a higher surface area of the biochar due to the release of $\mathrm{NH}_{3}$ to open the pores (Wan et al. 2020a). Mian et al. used melamine and sewage sludge to obtain $\mathrm{N}$-doped biochars via a pyrolysis process (Mian et al. 2020). The authors reported $9.5 \% \mathrm{~N}$ in the biochars with a specific surface area of $261.7 \mathrm{~m}^{2} / \mathrm{g}$.

Apart from nitrogenous chemicals, nitrogen-rich biomasses can also be used as the $\mathrm{N}$-source to dope nitrogen. Using nitrogen-rich biomass has the advantage of not using chemicals in the process. Moreover, these biomasses can be found as wastes in nature. For example, Yin et al. used Trapa natans husk to prepare biochar via pyrolysis (Yin et al. 2019). Aquatic animal wastes, shrimps, and crab bran were used as N-precursors due to their high protein content. According to the XPS results, the authors reported pyrrolic$\mathrm{N}$ and pyridinic-N-oxynitride on the biochar surface.

\subsection{Pre-treatment}

The pre-treatment of biomass (biomass treatment with chemicals before biochar preparation) usually involves surface oxygen modification to activate the biochar graphite layer and provide reactive oxygen sites for subsequent nitrogen incorporation. The defective carbon and oxygen provide active sites for N-modification (Wan and Li 2018). For example, ammonification of $\mathrm{H}_{2} \mathrm{O}_{2}$ preoxidized coconut shell-based biochar resulted in an increase of nitrogen content from 14.43 to $15.48 \mathrm{wt} \%$ compared to $\mathrm{N}$-doped biochar without peroxidation. Shafeeyan reported that air preoxidized palm shell-derived biochar on ammonification resulted in a significant $\mathrm{N}$ increase $(0.3-4.6 \%)$ in biochar with the formation of amide and pyridinic-N (Shafeeyan et al. 2011). Air could be employed after pretreating biomass with nitric acid (Kasnejad et al. 2012) or hydrofluoric acid (Zhang et al. 2015) to enhance the formation of oxidized 
nitrogen functional groups on biochar surface. Later, during pyrolysis, these oxygenated nitrogen functional groups are decomposed, increasing the activity of ammonia molecules and promoting the inclusion of $\mathrm{N}$-functional groups (Shafeeyan et al. 2011). Potassium hydroxide pretreatment has also been proven effective for enhanced $\mathrm{N}$ content in biochar. The pyrolysis of bamboo chips mixed with potassium hydroxide improved the nitrogen content from 0.3 to $7.0 \%$ in biochar (Chen et al. 2016).

In addition to biomass pretreatment, treatment of pristine biochar with oxidizing chemicals followed by nitrogen modification has also been reported. Seredych prepared N-modified biochar by peroxidizing pristine biochar with nitric acid followed by urea and melamine treatment at $950{ }^{\circ} \mathrm{C}$. The results showed that the nitrogen content of the preoxidized samples increased from 5.9 to $8 \%$ after melamine modifica- groups such as carbonyl and hydroxyl to produce $\mathrm{N}$-functional groups such as pyridinic-N, pyrrolic- $\mathrm{N}$, and graphitic$\mathrm{N}$. Thus, it is beneficial to have oxygen functionalities on the biomass surface which provides the site for the ammonia molecules to react. For example, Chen et al. reported that carbonyl groups on the biochar surface reacted with $\mathrm{NH}_{3}$ through Maillard reaction accompanied by $\mathrm{H}_{2}$ production (Chen et al. 2016). According to Jin et al., carboxyl groups might form $\mathrm{H}$-bonds with $\mathrm{NH}_{3}$ that favor $\mathrm{N}$-doping (Jin et al. 2020). Mian et al. linked the formation of amino groups $\left(\mathrm{R}-\mathrm{NH}_{2}\right)$ with the abundance of -OH groups in agar powder that reacted with $\mathrm{NH}_{3}$ molecules at high temperatures (Mian et al. 2018). After initial reactions of ammonia with the oxygen functionalities, the produced amino groups can undergo further transformation into pyridinic-N, pyrrolic-N, and graphitic- $\mathrm{N}$ species (Li et al. 2020).

$\mathrm{C}_{\text {biochar }}+\mathrm{NH}_{3} \rightarrow \mathrm{H}^{*}+\mathrm{C}^{*}+\mathrm{NH}^{*}+\mathrm{NH}_{2}{ }^{*} \rightarrow \mathrm{H}_{2}+\mathrm{C}-\mathrm{NH}+\mathrm{C}-\mathrm{NH}_{2}$

tion compared to samples without peroxidation (Seredych et al. 2008). Biochar activated with carbon dioxide before ammonification could also significantly enhance the nitrogen content in biochar and show better adsorption performance (Shao et al. 2018).

\subsection{Post-treatment approach}

In the post-treatment approach, the as-prepared biochar is treated with $\mathrm{N}$ dopants to incorporate $\mathrm{N}$ in the carbon lattice. This is achieved by thermal treatment of pristine biochar with ammonia gas or nitrogenous chemicals as well as ball milling treatment of biochar with nitrogenous chemicals. The dual thermal treatment might result in the collapse of biochar's pore structure. Thus, the temperature of treatment plays a vital role in shaping the resultant biochar's properties. It has been reported that treatment of pristine biochar with $\mathrm{N}$-precursors at lower temperatures results in chemically unstable $\mathrm{N}$ species in carbon material, whereas stable structural $\mathrm{N}$ is produced at higher temperatures ( $\mathrm{Li}$ et al. 2020).

$\mathrm{N}$-doping with ammonia gas purging is one of the most common ways to incorporate nitrogen functional groups in the biochar matrix. $\mathrm{NH}_{3}$ treatment of biochar might introduce amine- $\mathrm{N}$ groups, which can react with the O-functional groups on biochar resulting in multiple $\mathrm{N}$-functional groups and increasing the overall nitrogen content of biochar (Mian et al. 2018). The reaction occurs in the solid-gas interface and leads to incomplete N-doping, which results in the formation of aminated moieties on the surface, as shown in reaction 1 (Hou et al. 2019; Wu et al. 2020). In the process, free radicals, e.g., $\cdot \mathrm{NH}, \cdot \mathrm{NH}_{2}, \cdot \mathrm{H}$ generated at higher temperatures (around $500{ }^{\circ} \mathrm{C}$ ) may react with $\mathrm{O}$-functional
During the ammonification process, the properties of the resulting $\mathrm{N}$-doped biochar are heavily influenced by the thermal treatment temperature as well as residence times. The reactivity between ammonia molecules and the carbon frame is relatively low and requires a high temperature (Wan et al. 2020a). It has been reported that $700-900{ }^{\circ} \mathrm{C}$ is the effective treatment temperature for biochar ammonification. For example, Zhang et al. modified biochar with ammonia at different temperatures ranging from 500 to $900{ }^{\circ} \mathrm{C}$ and found that the $\mathrm{S}_{\mathrm{BET}}$ of biochar increased with increasing temperatures from 1.5 to $469 \mathrm{~m}^{2} / \mathrm{g}$, and the N-content was maximum at $800^{\circ} \mathrm{C}$ (Zhang et al. 2016). This might be due to the increased reactivity coupled with the introduction and decomposition of nitrogen functional groups at increasing temperatures. However, it is to be noted that due to gas purging, a large percentage of nitrogen is wasted. Moreover, high-temperature reactions increase the cost of biochar production with ammonia modifications.

In addition to ammonification, pristine biochars could be thermally treated with nitrogenous chemicals for $\mathrm{N}$-doping. Seredych et al. modified wood-based biochar with urea and melamine at $950{ }^{\circ} \mathrm{C}$ and reported an increase in nitrogen content from 0.2 to $5.1 \%$ and $5.9 \%$, respectively. However, the $\mathrm{N}$-speciation of the prepared biochars was different. The results suggested that urea-treated samples had an abundance of pyridinic-N, whereas melamine treatment was beneficial for generating graphitic-N (Seredych et al. 2008). On the other hand, Kasera et al. modified pine bark derived biochar with melamine and urea at $450{ }^{\circ} \mathrm{C}$ and reported an increase in $\mathrm{N}$ content from 0.37 to 8.3 and $2.9 \%$, respectively, but the results suggested that melamine treatment was beneficial for pyridinic- $\mathrm{N}$ and pyrrolic- $\mathrm{N}$ formation while urea treatment enhanced graphitic- $\mathrm{N}$ formation (Kasera et al. 2021). These 
suggest that factors such as treatment conditions, biochar feedstock, as well as the chemical structure of nitrogenous chemicals, influence the speciation of $\mathrm{N}$-functional groups in the modified biochar. Other than urea and melamine, Yang and Jiang (2014) modified sawdust-derived biochar with sulfuric and nitric acid for nitrification. The obtained solid was refluxed with ammonium hydroxide, sodium thiosulfate, and glacial acetic acid at $373 \mathrm{~K}$ for $5 \mathrm{~h}$ to obtain N-modified biochar (Yang and Jiang 2014). Wang et al. employed a grafting technique with polyethyleneimine on bamboo-derived biochar. The authors reported plenty of amine groups on the surface of obtained biochar (Wang et al. 2020).

Apart from thermal treatment of pristine biochar with nitrogenous chemicals, ball milling could also be employed to incorporate $\mathrm{N}$-functional groups on biochar surface. In ball milling, mechanical energy moving balls are utilized to break chemical bonds and produce fresh surfaces for reaction. $\mathrm{Xu}$ et al. prepared pristine biochar from bagasse and hickory chips at $450{ }^{\circ} \mathrm{C}$ and $600{ }^{\circ} \mathrm{C}$. After ball milling with ammonium hydroxide, the nitrogen content of bagasse biochar prepared at $450{ }^{\circ} \mathrm{C}$ increased from 0.3 to $1.79 \mathrm{wt} \%$, and hickory biochar increased from 0.97 to $2.24 \mathrm{wt} \%$. The incorporated $\mathrm{N}$ was located on the surface primarily in the form of amine- $\mathrm{N}$ and nitrile- $\mathrm{N}$ obtained by dehydration of oxygen-containing functional groups, as shown in reactions 2 and 3. However, the nitrogen contents of the biochars produced at $450{ }^{\circ} \mathrm{C}(2.41-2.65 \mathrm{wt} \%)$ were higher than that ofbiochars produced at $600{ }^{\circ} \mathrm{C}(1.18-1.82 \mathrm{wt} \%$ ) (Xu et al. 2019). This may be explained by the depletion of oxygen functional groups at higher pyrolysis temperatures leading to a decrease in possible reaction sites for ammonia hydroxide during ball milling treatment, inferring the importance of oxygen functional groups.
$2018 b)$. The authors reported $10 \%$ nitrogen in biochar with the successful introduction of pyrrolic-N, pyridinic-N, and graphitic-N on the surface. Similar observations were reported by $\mathrm{Yu}$ et al., who pyrolyzed municipal sewage sludge at $400{ }^{\circ} \mathrm{C}$ to obtain $\mathrm{N}$-doped biochar with $2.46 \%$ $\mathrm{N}$ with pyrrolic-N, pyridinic- $\mathrm{N}$, and graphitic-N species (Yu et al. 2019).

Hydrothermal carbonization is another common technique of fabricating biochar. In this process, heat is applied to biomass in water with elevated temperatures under autogenous pressure. Although the specific surface area of pyrolytically produced biochar is usually higher than that of hydrothermally derived biochars, the surface functional groups, which provide pollutant exchange sites, are fewer (Gai et al. 2016). Biochar produced from hydrothermal treatment of N-rich biomass also yields N-doped biochar. Lu et al. produced $\mathrm{N}$-doped biochar consisting of $2.7 \% \mathrm{~N}$ by hydrothermal carbonization of the seaweed Ulva prolifera at $200{ }^{\circ} \mathrm{C}$ for $4 \mathrm{~h}$ (Lu et al. 2017). Zhang et al. used pomelo peels as both nitrogen and carbon source to produce hydrothermally derived N-doped biochar (Zhang et al. 2020b).

Both pyrolysis and hydrothermal carbonization have been employed to produce $\mathrm{N}$-enriched biochar from nitrogendeficient biomass and a one-step process. Gai et al. hydrothermally treated rice husk in the presence of nitrogen-rich microalgae, Chlorella pyrenoidosa at $200{ }^{\circ} \mathrm{C}$ for $60 \mathrm{~min}$. The nitrogen content in the modified biochar increased from $1.28 \%$ (pristine biochar) to $7.37 \%$ (Gai et al. 2016). Lian et al. pyrolyzed corn straw at $600{ }^{\circ} \mathrm{C}$ for $2 \mathrm{~h}$ under $\mathrm{N}_{2}$ atmosphere $(200 \mathrm{~mL} / \mathrm{min})$ and then switched to $\mathrm{NH}_{3}$ atmosphere (200 $\mathrm{mL} / \mathrm{min})$. The researchers used different activation procedures such as elevated temperatures $\left(600-800^{\circ} \mathrm{C}\right)$ and residence times (1-3 h) to study the effects (Lian et al. 2016).

$-\mathrm{COOH}+\mathrm{NH}_{3} \cdot \mathrm{H}_{2} \mathrm{O} \stackrel{-\mathrm{H}_{2} \mathrm{O}}{\rightarrow}-\mathrm{COONH}_{4} \stackrel{-\mathrm{H}_{2} \mathrm{O}}{\rightarrow}-\mathrm{CO}-\mathrm{NH}_{2} \stackrel{-\mathrm{H}_{2} \mathrm{O}}{\rightarrow}-\mathrm{C} \equiv \mathrm{N}$

$-\mathrm{OH}+\mathrm{NH}_{3} \cdot \mathrm{H}_{2} \mathrm{O} \stackrel{-2 \mathrm{H}_{2} \mathrm{O}}{\rightarrow}-\mathrm{NH}_{2}$

\subsection{In-situ approach}

Pyrolysis is the most employed thermal technique to produce biochar from waste biomass. In this process, biomass is subjected to moderate to high temperatures $\left(350-800{ }^{\circ} \mathrm{C}\right)$ with little or no oxygen. The pyrolysis parameters such as temperature, atmosphere, residence time, and pressure affect the content and speciation of nitrogen functional groups of biochar (Leng et al. 2019). For nitrogen-rich biomass, the pyrolysis process alone yields $\mathrm{N}$-doped biochar. Yuan et al. pyrolyzed chitosan at $800{ }^{\circ} \mathrm{C}$ for $6 \mathrm{~h}$ to produce $\mathrm{N}$-doped biochar (Yuan et al.
Similarly, Zhu et al. mixed the stalk biomass in methanol with different $\mathrm{N}$ precursors such as urea, ammonium nitrate, melamine, yeast powder, and biopolymers of peptone (Zhu et al. 2020b). After evaporating the solvent, the solids were pyrolyzed at $450{ }^{\circ} \mathrm{C}$ for $90 \mathrm{~min}$ to obtain $\mathrm{N}$-doped biochars.

Recently, microwave-assisted pyrolysis has also been utilized to produce $\mathrm{N}$-doped biochars. Carbon materials are good microwave absorbents that are capable of converting the absorbed microwave radiation to heat energy (Lam and Chase 2012). Thus, biomass can be subjected to microwave radiation in the absence of oxygen to produce biochar. Wang et al. (2018) produced N-doped biochars by microwave pyrolysis of Phragmites australis immersed in phosphoric acid solution and mixed with either ammonium chloride or ammonium acetate at $700 \mathrm{~W}\left(450{ }^{\circ} \mathrm{C}\right)$ for $15 \mathrm{~min}$. The obtained biochars contained pyrrolic-N, pyridinic-N, and 
graphitic-N structures. In a different study, the authors employed the same technique to produce $\mathrm{N}$-doped biochars with different activators such as ammonium succinate, ammonium tartrate, and ammonium citrate.

Thus, $\mathrm{N}$-doped biochars can be fabricated using different techniques (pyrolysis, hydrothermal carbonization, and microwave process). Each of the processes has its own merits and demerits (Additional file 1: Table S1). When compared with the post-treatment route, the in-situ approach is much simpler and has the potential to engineer biochars with higher $\mathrm{N}$ content and stable $\mathrm{N}$-functional groups. But the pore structure of biochar is hard to control, and the yield of biochar may be reduced due to simultaneous chemical activation and $\mathrm{N}$ incorporation during pyrolysis. But comparative research on how these different techniques affect the nitrogen surface functionality and, ultimately, the end application has not been extensively undertaken yet, which needs researchers' attention.

\section{Surface chemical heterogeneity of $\mathrm{N}$-doped biochar}

Any adsorption process is significantly affected by the surface properties of the adsorbent. Hence, to understand $\mathrm{N}$-doped biochars' adsorption characteristics, it is imperative to discuss their surface properties. N-doped biochars are principally derived from biomass pyrolysis. Generally, $\mathrm{N}$-doped biochars are porous (meso and micro) carbonaceous materials having a high specific surface area with oxygen and nitrogen-containing functional groups on the surface. The structure of $\mathrm{N}$-doped biochar is shown in Fig. 3. Biochar surfaces exhibit both hydrophobic and hydrophilic properties as well as acidic and basic characteristics at the same time due to the heterogeneity of different functional

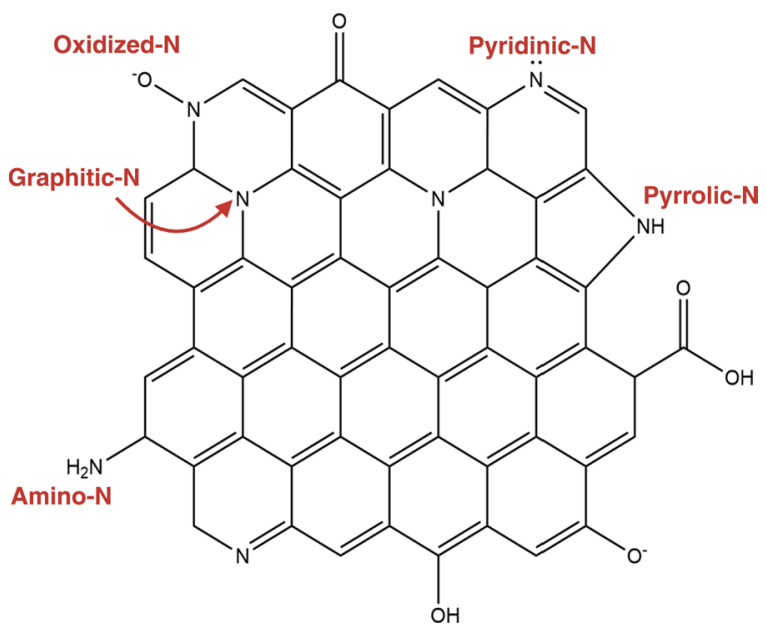

Fig. 3 Hypothetical structure of N-doped biochar groups present on the surface. The surface chemical heterogeneity arises due to the heteroatoms' electronegativity differences $(\mathrm{O}$ and $\mathrm{N})$ relative to adjacent $\mathrm{C}$ atoms. The types and extents of these surface functional groups depend primarily on the nature of biomass feedstock, $\mathrm{N}$-precursor as well as pyrolyzing conditions.

Biomass mainly consists of cellulose, hemicellulose, and lignin. Upon pyrolysis, the evaporable components, such as $\mathrm{H}_{2} \mathrm{O}, \mathrm{CO}_{2}, \mathrm{NO}_{x}, \mathrm{HCNO}, \mathrm{NH}_{3}, \mathrm{C}_{x} \mathrm{H}_{y} \mathrm{O}_{z}$, and others, are released, which is responsible for the porous characteristics of biochars. Proper development of pore structure is crucial to an adsorbent's success. Although it is not clear how feedstock may affect the surface area of $\mathrm{N}$-doped biochar, post modifications of biochar with nitrogenous chemicals may lead to pore blocking resulting in a decreased surface area (Li et al. 2020). Hence, different activation techniques have been utilized to increase the surface area of N-doped biochars. It has been reported that $\mathrm{NH}_{3}$ activation can etch the biochar surface by gas-solid reactions and increase the pore volume and surface area of biochar. For example, Zhang et al. reported an increase in $\mathrm{N}$ content and micropore volume of ammonia activated straw-derived biochar samples from $1.37 \mathrm{wt} \%$ and $0.10 \mathrm{~cm}^{3} / \mathrm{g}$ to $6.11 \mathrm{wt} \%$ and 0.19 $\mathrm{cm}^{3} / \mathrm{g}$ (Zhang et al. 2016). In addition to ammonification, the temperature of the reaction might also influence the surface area of N-doped biochars. For example, Luo et al. reported an increase in the surface area of $\mathrm{N}$-doped biochar samples with an increase in the reaction temperature (from 550 to $1000^{\circ} \mathrm{C}$ ) and residence time (2-6 h) (Luo et al. 2014). Additionally, an increase in pyrolyzing temperatures also causes an increase in the surface area. To quantify textural characteristics such as surface area, total pore volume, or mesopore volume, BET adsorption/desorption isotherm experiments are carried out. Moreover, SEM and TEM images are used frequently to visualize the physical morphology and porous structure of $\mathrm{N}$-doped biochars.

The origin of oxygen functionalities on the surface of N-doped biochars can be linked to biomass as well as $\mathrm{N}$-precursors having oxygen in them. These precursors, along with cellulose, hemicellulose, and lignin, undergo depolymerization and several other complex pathways such as dehydration, decarboxylation, aromatization, free radical generation, intermolecular condensation, and rearrangement to give rise to the solid biochar structure with oxygen functional groups in them. Detailed mechanisms of these pathways are reviewed elsewhere (Wan et al. 2020a). The oxygen-containing functional groups commonly present on the biochar exhibit both acidic and basic properties. The acidic type groups include phenol, carboxyl, carbonyl, lactone, and lactol, whereas chromene, pyrone, and quinone type structures exhibit basic properties. The acidic and basic oxygen functional groups on $\mathrm{N}$-doped biochars can be quantified using Boehm titration. Qualitative determination of 
these structures can be carried out via XPS and FTIR spectra of the samples.

Nitrogen in biochar originates either from the inherent nitrogen content of biomass (in the form of proteins) or the external nitrogen sources. Various forms of inorganic and organic nitrogen species can form depending on the feedstock and processing conditions. Among the inorganic forms of nitrogen, $\mathrm{NH}_{4}-\mathrm{N}, \mathrm{NO}_{3}-\mathrm{N}$, and $\mathrm{NO}_{2}-\mathrm{N}$ dominate (Liu et al. 2018). The organic forms of nitrogen in biochar include pyrrolic- $\mathrm{N}$, pyridinic- $\mathrm{N}$, amine- $\mathrm{N}$, amide- $\mathrm{N}$, nitrile$\mathrm{N}$, graphitic-N, and others (Chen et al. 2018c; Yuan et al. 2018a). The organic forms of nitrogen mainly exist in heterocyclic rings due to a series of complex chemical reactions between the inherent protein of biomass along with other biomass components or between biomass and external nitrogen sources (Leng et al. 2019). Moreover, the inorganic $\mathrm{N}$-functional groups can also convert to multiple heterocyclic rings. Organic $\mathrm{N}$-functional groups have high thermal stability. Among these, quaternary- $\mathrm{N}$ and pyridinic-N-oxide are the most stable, followed by pyridinic-N and pyrrolic-N (Tian et al. 2013; Leng et al. 2019).

The higher electronegativity of $\mathrm{N}$ (compared to $\mathrm{C}$ ) in biochar results in increased $\pi$-electron density favoring $\pi-\pi$ electron donor-acceptor interaction (Zhu et al. 2020b). The graphitic- $\mathrm{N}$ can act as an electron donor to facilitate a complexation reaction with heavy metals. Moreover, electron heterogeneity through $\mathrm{N}$-doping also enhances the persulfate activation through sorption and electron donors' presence. Besides, $\mathrm{N}$ having a lower electronegative than the oxygen atom may introduce extra functional groups and positive charges on the biochar matrix's edges. Nitrogen also enhances hydrophobicity in biochar (Zhu et al. 2020b). These chemical properties of N-doped biochars, along with their porous characteristics, make them a promising industrial adsorbent for the remediation of pollutants.

\section{Adsorption performance of $\mathrm{N}$-doped biochars}

Adsorption is, essentially, the immobilization of contaminants on the adsorbent surface. It is imperative for an adsorbent to attract the pollutants overcoming the mass transfer barrier between different phases. $\mathrm{N}$-doped biochars have been studied to test the removal of a wide range of toxic contaminants, which can be broadly categorized into heavy metals $(\mathrm{Pb}, \mathrm{Cd}$, Chromium $(\mathrm{Cr})$, etc.), organics (atrazine, methylene blue, acid red, etc.), and acid gases $\left(\mathrm{CO}_{2}, \mathrm{SO}_{2}\right.$, etc.). The aqueous contaminants (heavy metals and organics) present themselves in ionic forms or as charged particles, providing opportunities to tailor the surface properties of adsorbents to contain opposite charges, thus facilitating attractive interactions for the removal of these contaminants from the solution. Besides surface properties, the adsorbents' porous characteristics are also of great importance as they provide a path for the diffusion of the contaminants from a liquid or gaseous phase to the solid adsorbents. As discussed in Sect. 3, N-doped biochars have diverse surface functionalities with a porous structure. $\mathrm{N}$-doping also enhances the basicity on the biochar surface, which assists in electrostatic attraction (Wan et al. 2020b). These factors promote the adsorption of a wide range of contaminants on $\mathrm{N}$-doped biochar, making it a promising industrial adsorbent. However, N-modified biochars' surface and porous characteristics depend on preparation conditions. For example, preparing biochars at high temperatures enhances the porous characteristics because of the volatilization of organics, but it compromises surface functionality (Abbas et al. 2018). Therefore, to achieve optimal removal performance by $\mathrm{N}$-doped biochars, a balance between their surface functionalities and pores is desired.

\subsection{Adsorption of heavy metals}

Heavy metals are toxic to humans as well as aquatic species (Ali et al. 2011; Al-Abachi et al. 2013). Thus, it is crucial to find economical and environment-friendly routes for heavy metal removal from industrial effluents. The electroactive moieties on the biochar surface play a pivotal role in the adsorption of metals. The basic sites introduced by $\mathrm{N}$-doping provide unpaired electrons to undergo complex formation with metals. Thus, N-doped biochars exhibit good adsorption affinities towards heavy metals. The adsorption characteristics of heavy metals by $\mathrm{N}$-doped biochars are summarized in Table 3. Mian et al. reported $\mathrm{Cr}(\mathrm{VI})$ adsorption capacity of $142.9 \mathrm{mg} / \mathrm{g}$ on $\mathrm{NH}_{3}$ activated agar derived biochar due to improved electrostatic attraction by $\mathrm{N}$-dopants (Mian et al. 2018). N-doping could also enhance the hydrophilicity of biochar which provides better contact opportunity between metal ions in solution and biochar surface. $\mathrm{Yu}$ et al. studied the adsorption of $\mathrm{Cu}^{2+}$ and $\mathrm{Cd}^{2+}$ on $\mathrm{N}$-doped biochars (Yu et al. 2018). NBC800-3 (carbonization temperature: $800{ }^{\circ} \mathrm{C}$, retention time: $3 \mathrm{~h}$ ) achieved $97.7 \%$ and $88.1 \%$ removal of $\mathrm{Cu}^{2+}$ and $\mathrm{Cd}^{2+}$,respectively, from solution within $1 \mathrm{~h}$, which indicated a strong binding affinity of heavy metals towards N-doped biochars. The authors opined surface complexation with graphitic- $\mathrm{N}$ and surface $\mathrm{OH}$ groups to be the governing adsorption mechanism. The maximum adsorption capacities for $\mathrm{Cu}^{2+}$ and $\mathrm{Cd}^{2+}$ were reported to be $146.8 \mathrm{mg} / \mathrm{g}$ and $197.8 \mathrm{mg} / \mathrm{g}$. The adsorption capacities did not correlate well with either the total nitrogen content or the $S_{B E T}$ of the sample. However, a positive correlation was reported between the adsorption capacities and graphitic$\mathrm{N}$ content of the sample $\left(\mathrm{R}^{2}=0.948\right.$ for $\mathrm{Cd}^{2+}$, and 0.727 for $\mathrm{Cu}^{2+}$, respectively). Moreover, a significant decrease in graphitic-N after adsorption was confirmed by XPS analysis 


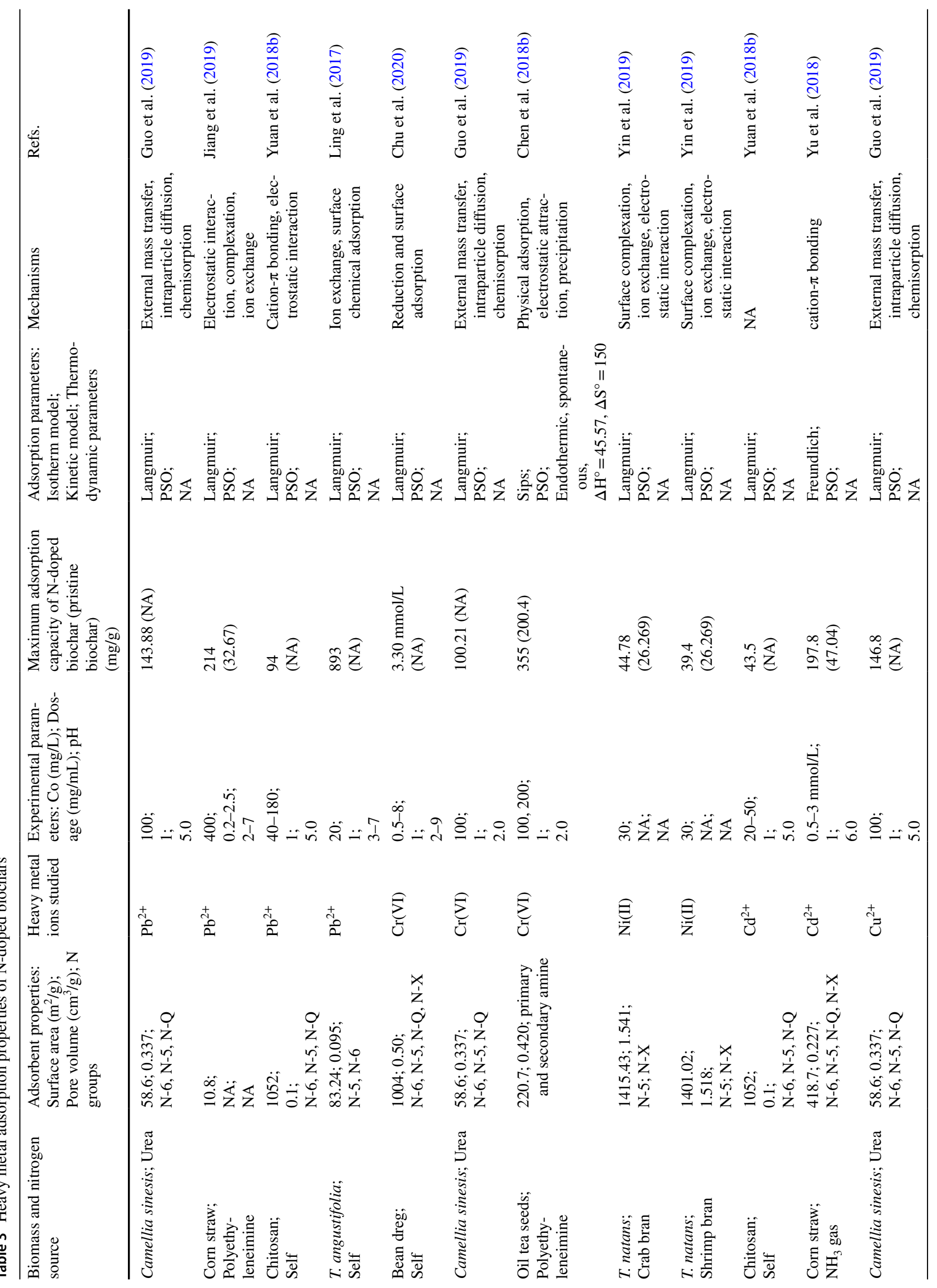


of the spent samples suggesting that the graphitic- $\mathrm{N}$ content of $\mathrm{N}$-doped biochar samples was instrumental in heavy metal adsorption. Previously it was discussed that N-doped biochars prepared at high temperatures exhibit high graphitic-N in the structure. Guo et al. studied heavy metal adsorption on $\mathrm{N}$-doped biochar prepared by hydrothermal carbonization of Camellia sinensis as a function of temperature. The biochar prepared at $240{ }^{\circ} \mathrm{C}$ (HTC-240) showed maximum adsorption capacity for $\mathrm{Cu}(43.98 \mathrm{mg} / \mathrm{g}), \mathrm{Pb}(83.91 \mathrm{mg} / \mathrm{g})$, and $\mathrm{Cr}$ $(94.69 \mathrm{mg} / \mathrm{g})$, whereas biochar prepared at $280{ }^{\circ} \mathrm{C}$ (HTC280) showed maximum adsorption towards $\mathrm{Zn}(64.78 \mathrm{mg} / \mathrm{g})$. Although a specific explanation of this phenomenon was not provided, the authors indicated that the complex formation of metal ions with $\mathrm{N}$-doped biochar combined with external mass transfer and intraparticle diffusion through biochar micropores were responsible for the heavy metal adsorption (Guo et al. 2020). Gai et al. also studied $\mathrm{Cu}$ removal by $\mathrm{N}$-doped biochars and reported an enhanced adsorption capacity of $104.3 \mathrm{mg} / \mathrm{g}$ compared to $13.1 \mathrm{mg} / \mathrm{g}$ for pristine biochar (Gai et al. 2016). The researchers found that the $\mathrm{N}-\mathrm{H}$ stretching peak was shifted from $3407 \mathrm{~cm}^{-1}$ in the modified biochar to $3381 \mathrm{~cm}^{-1}$ after $\mathrm{Cu}$ adsorption, which indicated the involvement of amino groups in $\mathrm{Cu}$ removal from the solution. The authors argued in favor of the enhanced basicity due to the anchoring of basic amino groups and increased hydrophobicity, which decreased the competition between protons and $\mathrm{Cu}$ ions for active surface sites. Also, the nitrogen modification promoted the high binding affinity of metal ions as nitrogen can share electrons during complex formation, resulting in a better adsorption performance of $\mathrm{N}$-doped biochar than pristine biochar. Jiang et al. reported a high adsorption capacity of $\mathrm{N}$-doped biochars $\left(214.0 \mathrm{mg} / \mathrm{g}\right.$ ) for $\mathrm{Pb}^{2+}$ removal (Jiang et al. 2019). This high adsorption capacity was attributed to N-functionalities of the surface of biochar. The authors reported an increase in the binding energy of $\mathrm{N}$-moieties after $\mathrm{Pb}^{2+}$ adsorption, as confirmed by the XPS results. This might be caused formation of hydrogen bonds or nitrogen chelation with $\mathrm{Pb}^{2+}$. Yuan et al. reported a decrease in surface N-content from 9.6 to 7.5 atomic\% after $\mathrm{Pb}^{2+}$ adsorption (Yuan et al. 2018b). The basic $\mathrm{N}$-functional groups like pyrrolic-N and pyridinic-N can coordinate strongly with acidic, heavy metal ions, while the graphitic-N structures can share the lone pair electrons with $\mathrm{Pb}^{2+}$ enhancing the adsorption performance (Sawant et al. 2017; Yu et al. 2018). In addition to $\mathrm{Cu}, \mathrm{Pb}$, and $\mathrm{Cd}, \mathrm{Cr}(\mathrm{VI})$ adsorption was also studied with $\mathrm{N}$-doped biochar. Chu et al. reported a $\mathrm{Cr}$ adsorption capacity of $3.30 \mathrm{mmol} / \mathrm{L}$ on bean dreg-derived $\mathrm{N}$-doped biochar. The authors reported that $\mathrm{Cr}(\mathrm{VI})$ was reduced to $\mathrm{Cr}(\mathrm{III})$ on the biochar's surface (Chu et al. 2020). Cr reduction and adsorption by N-doped biochars were also reported by Zhu et al. (2020b). The authors demonstrated that persistent free radicals on $\mathrm{N}$-doped biochar, which acted as electron donors, 
were responsible for $\mathrm{Cr}(\mathrm{VI})$ reduction to $\mathrm{Cr}$ (III). These studies suggest that $\mathrm{N}$-doped biochars have a promising potential to be used as an industrial adsorbent for heavy metal removal.

\subsubsection{Heavy metal adsorption mechanism}

The removal of heavy metals by $\mathrm{N}$-doped biochars cannot currently be explained by a single straightforward mechanism (Table 3). This is due to the presence of surface functionalities on biochar in varied chemical forms. However, it is widely regarded that the heavy metal adsorption by biochars is not much affected by the porous characteristics (Yu et al. 2018). Hence, the adsorption is largely dependent on the surface functionalities, which interact with the heavy metals through different routes, including complexation, cation-pi bonding, ion exchange, electrostatic interaction, and precipitation. These mechanisms are visualized in Fig. 4.

Complexation Complexation is the most widely reported mechanism for removing heavy metals by $\mathrm{N}$-doped biochars (Table 3). Complexation requires the formation of multiatom structures through specific metal-ligand interactions. The partially filled d-orbitals of transition metals (e.g., Cd, $\mathrm{Cu}, \mathrm{Ni}$, and $\mathrm{Pb}$ ) have a high affinity for ligands (Crabtree 2009). The nitrogen present in N-doped biochars can share their lone pair electrons to these partially filled d-orbitals of the heavy metals, forming a complex-coordinate structure. In addition to $\mathrm{N}$-functionality, surface oxygen-functional groups of biochar (e.g., carboxyl, phenolic, and lactonic) can bind with metals through complexation (Mohan et al. 2007; Liu and Zhang 2009).

Cation- $\pi$ bonding Cation- $\pi$ interactions between heavy metals and N-doped biochars have also been reported (Yuan

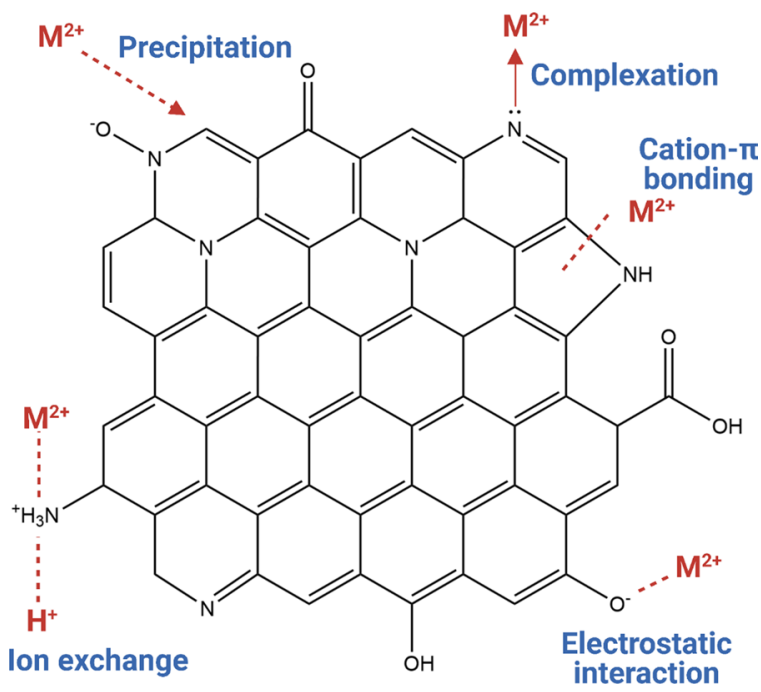

et al. 2018b; Yu et al. 2018). It is the non-covalent bonding interaction between the face of an electron-rich $\pi$ system and the adjacent cations governed by electrostatics. $\mathrm{N}$-doping can enhance the cation- $\pi$ interaction between biochar and heavy metals. For example, the electron-donating amino group $\left(-\mathrm{NH}_{2}\right)$ can strengthen the cation- $\pi$ interaction (Mecozzi et al. 1996). Moreover, heterocyclic structures like pyrrole also contribute positively towards cation- $\pi$ bonding by incorporating the lone pair electron of nitrogen in the aromatic system. However, pyridine does not contribute to aromaticity but withdraws electrons from the aromatic ring due to nitrogen's electronegativity, weakening the cation- $\pi$ binding ability ( $\mathrm{Ma}$ and Dougherty 1997).

Precipitation Precipitation involves the formation of solid products, either on the biochar surface or in solution during the adsorption process. It is considered one of the principal mechanisms for the removal of heavy metals by biochar adsorbents. Metals like $\mathrm{Cu}, \mathrm{Zn}, \mathrm{Ni}$, and $\mathrm{Pb}$ are more likely to precipitate on biochar surfaces than other elements (Inyang et al. 2016). It has been reported that alkaline biochars may induce metallic species' precipitation (Inyang et al. 2010). Although N-doping is not directly related to precipitation, it enhances biochar basicity and may aid in the precipitation of heavy metals on the biochar surface. For example, Yang et al. reported precipitation to be one of the mechanisms for removing $\mathrm{Cu}$ ions from solution by amino-modified biochars (Yang and Jiang 2014).

Ion exchange Another possible mechanism for heavy metal immobilization by biochars is through the exchange of ionizable protons/cations with the dissolved metallic contaminants. Ion exchange capacity is influenced by the size of the contaminant as well as biochar surface functionality. Surface functionalities control the cation exchange capacity (CEC) of biochars. A high CEC is indicative of the enhanced metal removal potential (Rizwan et al. 2016; Ali et al. 2017). Yin et al. reported Ni removal from solution by $\mathrm{N}$-doped biochars through ion exchange mechanism (Yin et al. 2019). The possible reactions are as follows:

surface $-\mathrm{NH}_{2}+\mathrm{H}^{+} \leftrightarrow$ surface $-\mathrm{NH}_{3}^{+}$

surface $-\mathrm{NH}_{3}^{+}+\mathrm{Ni}^{2+} \leftrightarrow$ surface $-\mathrm{NH}_{2} \mathrm{Ni}^{+}+\mathrm{H}^{+}$

Electrostatic interaction Electrostatic interaction occurs between the deprotonated surface oxygenated groups (e.g., phenolic and carboxylic groups) and metal ions. This is highly dependent on the $\mathrm{pH}$ of the solution and the point of zero charges (PZC) of the biochar, which is discussed in detail in Sect. 6.1. The possible reaction between metal ions and deprotonated oxygen functional groups can be written as follows (Yin et al. 2019):

Fig. 4 Heavy metal adsorption mechanisms by N-doped biochar 
surface $-\mathrm{OH} \leftrightarrow$ surface $-\mathrm{O}^{-}+H^{+}$

surface $-O^{-}+M^{2+} \leftrightarrow$ surface $-O^{-} M^{2+}$

surface $-\mathrm{COOH} \leftrightarrow$ surface $-\mathrm{COO}^{-}+\mathrm{H}^{+}$

surface $-\mathrm{COO}^{-}+\mathrm{M}^{2+} \leftrightarrow$ surface $-\mathrm{COO}^{-} \mathrm{M}^{2+}$

\subsection{Adsorption of organic chemicals}

Similar to heavy metals, organic chemicals, including dyes and pharmaceuticals, in water bodies are detrimental to the natural environment. $\mathrm{N}$-doped biochar has been studied for organic chemicals removal from water as well, which is summarized in Table 4. It has been reported that the content of nitrogen in biochar correlated positively with the adsorption of organic pollutants. For example, Yang et al. modified biochar with $\mathrm{LiNO}_{3}$, which resulted in an increase of nitrogen from 1.03 to $4.28 \%$ in biochar, improving adsorption of atrazine from 268 to $283 \mathrm{mg} / \mathrm{g}$ due to interaction between $\mathrm{N}$-functional groups $(\mathrm{N}-\mathrm{H}, \mathrm{C}=\mathrm{N}$, and $\mathrm{C}-\mathrm{N})$ and atrazine (Yang et al. 2017). Similarly, an increase in nitrogen content from 2.3 to $8.4 \%$ in biochar enhanced the formaldehyde adsorption capacity from 3.27 to $14.34 \mathrm{mg} / \mathrm{g}$, probably due to the reaction between formaldehyde and amine functional groups on biochar (Lee et al. 2013; Shen and Fan 2013). Lu et al. studied the adsorption of bisphenol A on Ulva prolifera based N-doped biochar. More than $90 \%$ of bisphenol A was removed in the first $4 \mathrm{~h}$ (Lu et al. 2017). The adsorption capacity reached $9.19 \mathrm{mg} / \mathrm{g}$ in these $4 \mathrm{~h}$ and then saturated at $9.92 \mathrm{mg} / \mathrm{g}$ in $24 \mathrm{~h}$. Adsorption followed second-order kinetics and the Langmuir model. Based on the Langmuir model, the maximum adsorption capacity was found to be $33.33 \mathrm{mg} / \mathrm{g}$. The increased basicity of biochar due to N-doping facilitated its affinity towards acidic bisphenol A. It was also reported that the adsorption capacity increased from 33.3 to $84.19 \mathrm{mg} / \mathrm{g}$ when the temperature increased from 25 to $45^{\circ} \mathrm{C}$, indicating the endothermic nature of the reaction. Li et al. studied phenol adsorption on corn stalk and urea-based biochar and reported an adsorption capacity of $95.9 \mathrm{mg} / \mathrm{g}$ (Li et al. 2019). Both Lewis acid-base interactions, as well as $\pi-\pi$ electron donor and acceptor (EDA) interaction, were responsible for the removal of phenol. Urea had an activating effect on the porous characteristics of biochar. Phenol was adsorbed rapidly in the first $60 \mathrm{~min}$ and then slowed between 60 and $480 \mathrm{~min}$. The authors reported that equilibrium was achieved after $720 \mathrm{~min}$. XPS analysis of spent biochar suggested that the content of pyridinic$\mathrm{N}$ and pyrrolic $\mathrm{N}$ decreased from 2.1 and 4.0 to 1.8 and $3.2 \%$, respectively, after phenol adsorption, suggesting a possible reaction between phenol and $\mathrm{N}$-species. Yin et al. studied the adsorption of 2,4-DCP using in-situ N-doped biochar modified with shrimp and crab bran (Yin et al. 2019). Both shrimp and crab modified samples showed a superior adsorption ability towards 2,4-DCP with adsorption capacities of $863.24 \mathrm{mg} / \mathrm{g}$ and $728.69 \mathrm{mg} / \mathrm{g}$, respectively. Changes in amino group intensity in the FTIR spectra of spent carbon suggested that the amino group might enhance 2,4-DCP adsorption. In addition to amino groups, $\mathrm{C}-\mathrm{O}$ and $\mathrm{C}=\mathrm{O}$ groups also participated in the adsorption reaction. Wang et al. studied the adsorption of acid red-18 on ammonium acetate-activated $\mathrm{N}$-doped biochar (Wang et al. 2018). The sample's adsorption capacity was reported to be $115.83 \mathrm{mg} / \mathrm{g}$ with an equilibrium time of $11.6 \mathrm{~h}$. XPS analysis on spent $\mathrm{N}$-doped biochar samples revealed a reduction in the pyrrolic-N content ratio from 64 to $58.30 \%$. Besides, the pyridinic-N peak shifted to lower binding energy suggesting that pyridinic-N interacted with acid red 18 . These studies indicate that $\mathrm{N}$-doped biochar is effective for removing a wide range of organic chemicals, likely for a variety of reasons.

\subsubsection{Organic pollutant adsorption mechanism}

Analogous to the heavy metal removal mechanism by $\mathrm{N}$-doped biochars, the removal of organic chemicals by $\mathrm{N}$-doped biochars cannot be explained by a simple mechanism as well. Unlike metals, organic pollutants are more nucleophilic because of their electron-rich molecular arrangements, which provide opportunities for $\mathrm{N}$-doped biochar to promote adsorption via $\pi-\pi$ EDA interaction as well as Lewis acid-base interactions. Moreover, doping nitrogen on aromatic carbon rings of biochar creates positive holes due to electronegativity differences which may also attract electron-rich organic pollutants. However, the adsorption of organics on $\mathrm{N}$-doped biochars depends both on the pore characteristics as well as surface functionalities. The mechanisms of organics removal by $\mathrm{N}$-doped biochars are summarized in Fig. 5.

Pore filling The physical attributes of adsorbents, including the specific surface area, total pore volume, micro, and mesoporous channels, influence their adsorptive properties. Thus, the existence of micropores $(<2 \mathrm{~nm})$ and mesopores $(2-50 \mathrm{~nm})$ on biochar surfaces govern the applicability porefilling mechanism in the adsorption of organic pollutants (Pignatello et al. 2006; Nguyen et al. 2007; Hao et al. 2013). The mesopores provide the channels for diffusion of the pollutants, thus reducing the mass transfer resistances, while the micropores provide the space for the adsorption of these contaminants (Wang et al. 2018). Generally, adsorbents having pore sizes 1-2 times higher than the adsorbate show good adsorption performance (Lorenc-Grabowska et al. 2016). Hence, depending on biochar's type and physical attributes, pore-filling mechanisms can facilitate the removal of both 


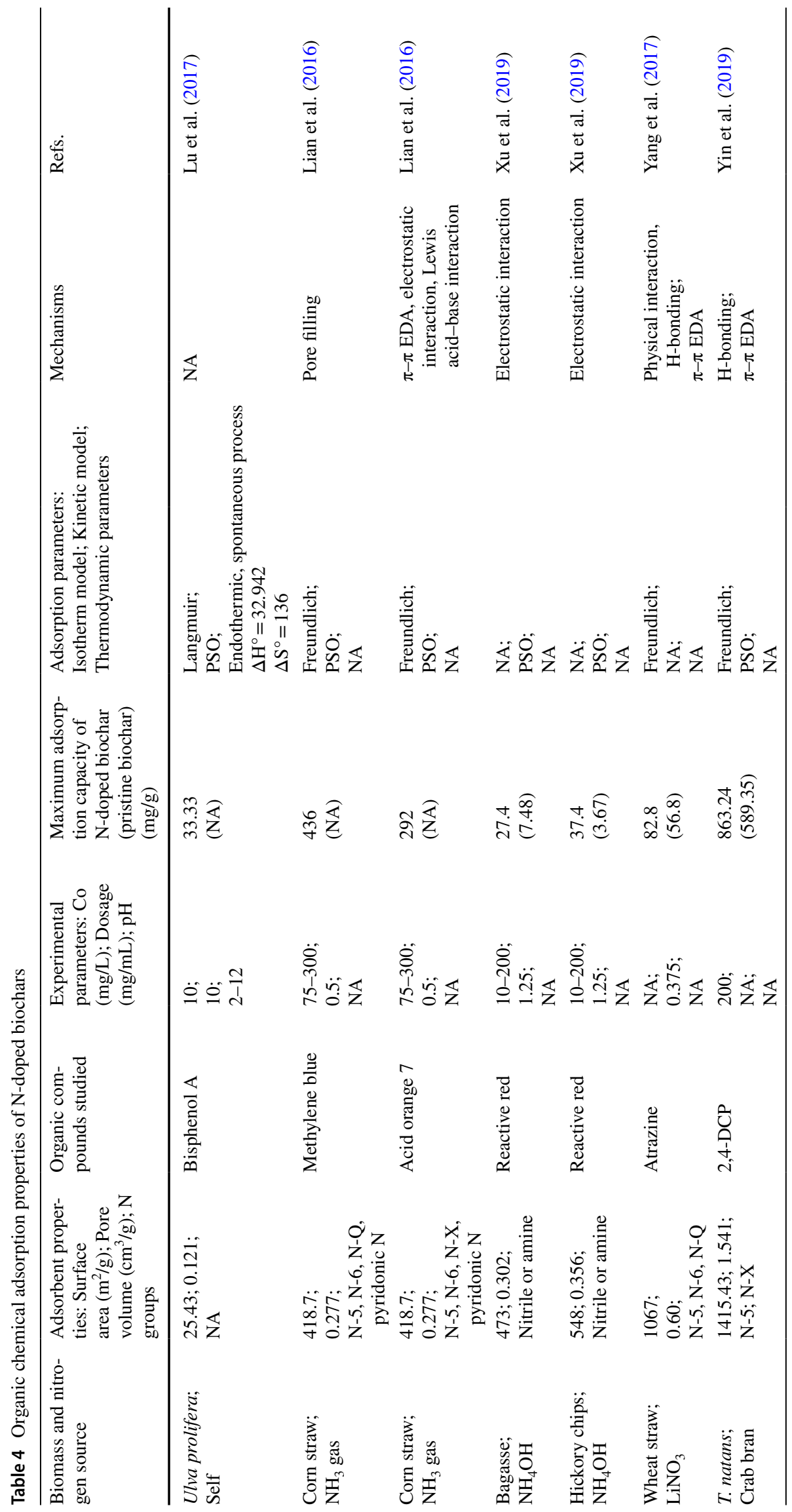




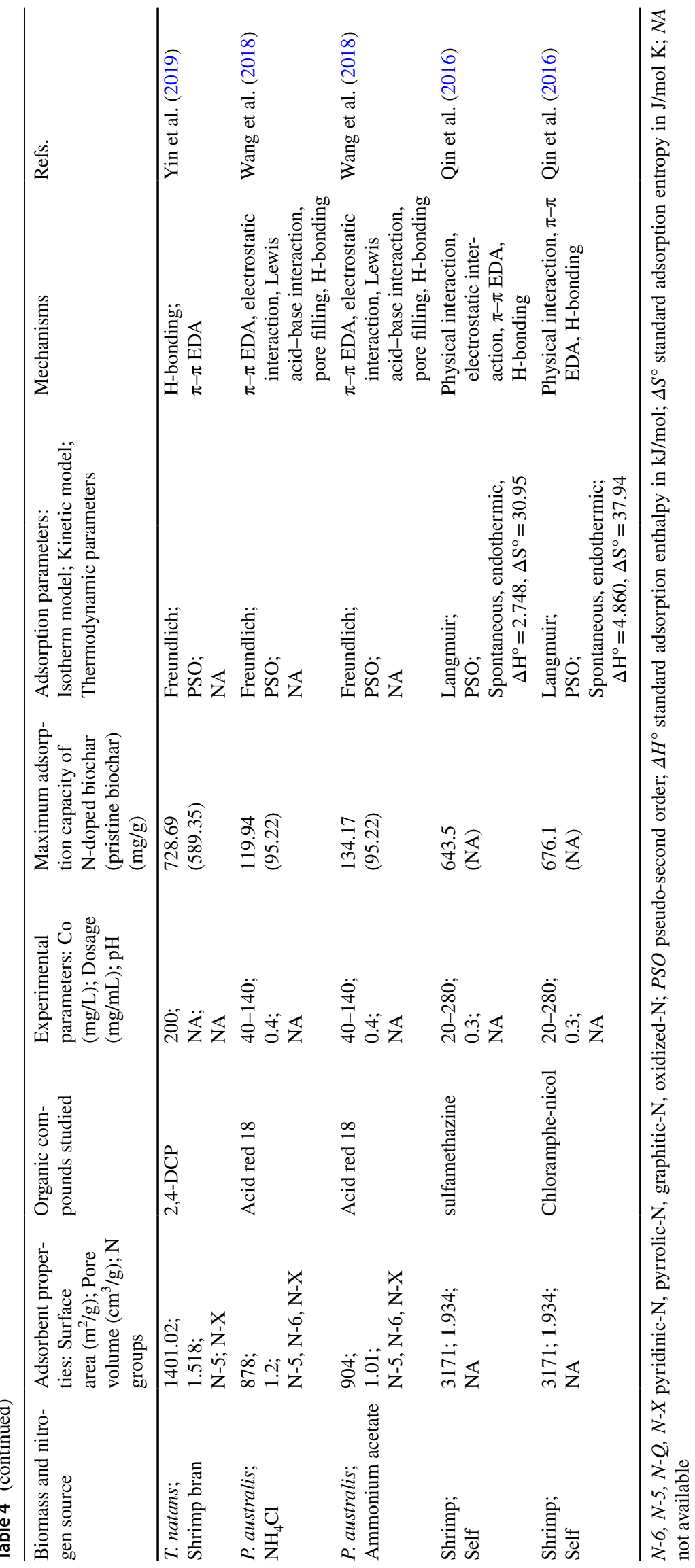




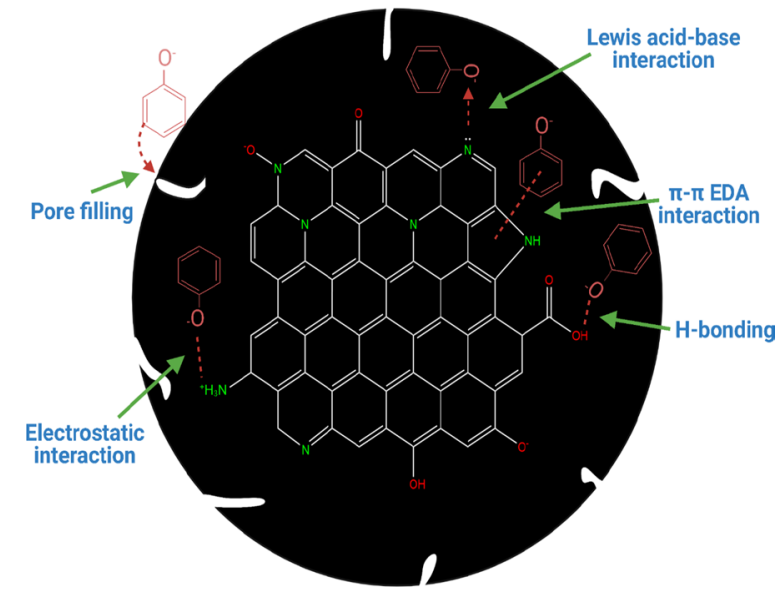

Fig. 5 Organic chemical adsorption mechanism options by N-doped biochar

polar and nonpolar organic contaminants. In the adsorption of phenol by a corn stalk-derived N-doped biochar, the surface area and pore volume decreased by $32.6 \%$ and $31.6 \%$, respectively, after adsorption (Li et al. 2019). Similar observations were reported in a study involving removal of acid red 18 using ammonium acetate activated $\mathrm{N}$-doped biochar where the pore volume of different samples decreased by 16.18-28.26\% after adsorption (Wang et al. 2018). Although pore filling is not the principal mechanism involved in the removal of organic pollutants via $\mathrm{N}$-doped biochars, these results suggest that a well-developed porous biochar surface might provide additional advantages alongside an abundance of functional groups in the pollutant removal process.

Hydrogen bonding Hydrogen bonding is a particular type of dipole-dipole attraction that occurs between a hydrogen donor and acceptor. Hydrogen donors are the electronegative molecules such as nitrogen, oxygen, and fluorine to which hydrogen is covalently bound. On the other hand, hydrogen acceptors are other electronegative molecules having a lone pair of electrons. These hydrogen donor and acceptor functional groups $\left(-\mathrm{NH}_{2},-\mathrm{OH},-\mathrm{COOH}\right.$, etc.), present on the surface of N-doped biochars, can immobilize organic pollutants through hydrogen bonding. For example, Yin et al. reported the existence of hydrogen bonds between 2,4-DCP and $\mathrm{O} / \mathrm{N}$ functional groups on $\mathrm{N}$-doped biochars (Yin et al. 2019). Similarly, Yang et al. discussed hydrogen bonding to be one of the responsible chemical interactions to adsorb atrazine on N-doped biochar (Yang et al. 2017).

$\pi-\pi$ electron donor and acceptor (EDA) interaction $\pi-\pi$ EDA interactions are essential for the adsorption of planar aromatic pollutants on graphene-like biochar surfaces (Wang et al. 2017). According to Spokas (Kurt 2010), a temperature $>1100{ }^{\circ} \mathrm{C}$ is required for the complete graphitization of biochar. However, incomplete graphitization leads to irregular sharing of charge between the aromatic rings of biochar. This results in either an increase or decrease of electron density, forming $\pi$ electron-rich or $\pi$ electron-deficient regions inside biochar. These electron-rich or deficient systems can either donate or accept electrons from aromatic contaminants through the $\pi-\pi$ EDA interactions. N-doping on biochar may enhance these interactions. For example, Wang et al. reported that nitrogen functional groups withdrew the $\pi$-electrons from the graphene layer, creating positive surroundings, which might act as $\pi$-electron-acceptors and interact with $\pi$-electron-enriched aromatic rings of acid red 18 (Wang et al. 2018). A similar interaction was reported by $\mathrm{Li}$ et al. where phenol acted as a $\pi$-electron donor in a $\pi-\pi$ EDA interaction facilitated by nitrogen functional groups on biochar (Li et al. 2019).

Lewis acid-base interaction In addition to the $\pi-\pi$ EDA interactions between $\mathrm{N}$-doped biochar and organic pollutants, Lewis acid-base interactions have also been reported. $\mathrm{N}$-doped biochar contains moieties that can donate electrons (N-functional groups, O-functional groups) and act as Lewis bases. On the other hand, the electron withdrawal effect of nitrogen may create Lewis acid surrounding as well. XPS studies of $\mathrm{N}$-doped biochar after adsorption of organic pollutants revealed changes in contents of $\mathrm{N}$-functionalities and a shift in the binding energies, which indicates Lewis acid-base interactions (Wang et al. 2018; Li et al. 2019).

Electrostatic interaction Electrostatic interaction involves the attraction of opposite charges from the ionizable functional groups of organic pollutants and biochar's surface. Similar to heavy metals, the electrostatic removal mechanism of organics through biochar is also dependent on solution $\mathrm{pH}$.

\subsection{Catalytic degradation of organic pollutants by $\mathrm{N}$-doped biochar}

In addition to adsorption, advanced oxidation processes (AOPs) could also be employed to remove organic pollutants via $\mathrm{N}$-doped biochar. AOPs utilize appropriate catalysts and oxidizing agents (e.g., persulphates, peroxides, and ozone) to potentially reach complete removal of the pollutants under suitable reaction conditions (Wan et al. 2020b). Various carbonaceous materials such as graphene, carbon nanotubes, and biochar are investigated for their electrochemical properties to be used as catalysts in AOPs. The presence of nitrogen functionalities on the biochar surface is a desirable property for catalytic persulphate activation (Ho et al. 2019). For example, unpaired electrons of pyridinic-N and pyrrolic-N could capture the electrophilic peroxide molecules (Duan et al. 2018). Additionally, due to the electronegativity difference between $\mathrm{N}$ and $\mathrm{C}$ atoms, the peroxide molecules could be adsorbed on positively charged $\mathrm{C}$ atoms and accept electrons from adjacent nitrogen. Graphitic-N with n-type conduction enhances the catalyst reactivity towards electron acceptor molecules (Zaeni 
et al. 2020). Moreover, it has been reported that the presence of nitrogen functionalities could lower the dissociation energy threshold of peroxide O-O bond (Duan et al. 2018). N-doped biochar enhanced the removal rate of different pollutants by catalytic persulphate activation such as orangeG (Zhu et al. 2018), hyaluronic acid (Xu et al. 2018), sulfadiazine (Wang et al. 2019b), and tetracycline (Zhong et al. 2020). Although $\mathrm{N}$-doping enhanced pollutant degradation, researchers have attributed different $\mathrm{N}$-functionalities for the catalytic activity in their reported work. For example, Wang et al. are of the opinion that pyrrolic and pyridinic $\mathrm{N}$ are responsible for the enhancement in sulfadiazine removal ability (Wang et al. 2019b), while $\mathrm{Yu}$ et al. reported that pyridinic-N and graphitic-N were related to increased tetracycline removal ability (Yu et al. 2019). According to Zhu et al. (2018) Graphitic-N showed better catalytic activity towards removing orange $\mathrm{G}$ (Zhu et al. 2018). However, it is to be noted that the catalytic activity of biochar for persulphate activation does not entirely depend on the nitrogen functionalities but also on the pore structure and surface area (Leng et al. 2019). Also, the reaction rate for pollutant degradation could be significantly influenced by operational parameters such as catalyst loading, peroxide dosage, and $\mathrm{pH}$. Thus, further research is needed involving systemic studies elucidating the effect of these factors on pollutant degradation as well as the mechanism of nitrogen functionalities in catalytic activities to improve performance.

\section{Adsorption characteristics}

\subsection{Adsorption isotherm}

Adsorption equilibrium provides vital information for the complete understanding of adsorption processes (Ayawei et al. 2017). Adsorption isotherm describes the mathematical relationship between the equilibrium concentration of solute or adsorbate on the surface of adsorbent and the concentration of solute in its solution (Sahu and Singh 2018). Hence, a complete understanding of adsorption isotherms is critical to elucidate the adsorption mechanisms and pathways for effective designs of adsorption systems (El-Khaiary 2008). Several isotherm models have been proposed for analyzing adsorption equilibrium data, including Langmuir, Freundlich, Sips, Redlich-Peterson, and others (Sahu and Singh 2018). Among them, Langmuir and Freundlich's models are the most popular for explaining the adsorptive removal of contaminants from wastewater by activated carbon (Wu et al. 2009). The equations for different isotherm models are provided below (Inyang et al. 2016):

Langmuir : $q_{e}=\frac{q_{\max } b C_{e}}{1+b C_{e}}$
Freundlich : $q_{e}=K_{f} C_{e}^{\frac{1}{n}}$

Sips : $q_{e}=\frac{K_{S} C_{e}^{\beta_{S}}}{1+a_{S} C_{e}^{\beta_{S}}}$

Redlich-Peterson $: q_{e}=\frac{K_{1} C_{e}}{1+K_{2} C_{e}^{\beta}}$

where, $q_{e}(\mathrm{mg} / \mathrm{g})$ is the equilibrium loading of pollutant on biochar, $C_{e}(\mathrm{mg} / \mathrm{L})$ is the aqueous concentration of pollutants at equilibrium, $q_{\max }$ is the maximum monolayer adsorption capacity $(\mathrm{mg} / \mathrm{g}), b(\mathrm{~L} / \mathrm{mg})$ is in relation to the binding energy, $K_{f}(\mathrm{~L} / \mathrm{mg})$ is the Freundlich adsorption capacity, $1 / n$ is the adsorption intensity, $K_{s}(\mathrm{~L} / \mathrm{mg})$ is Sips equilibrium constant, $a_{S}$ is the Sips model constant, $\beta_{S}$ is the Sips model exponent, $K_{1}$ and $K_{2}$ are Redlich-Peterson isotherms constants, and $\beta$ is the isotherms exponent.

Langmuir model assumes uniform monolayer adsorption of solutes on a homogeneous adsorbent surface having a number of specific adsorption sites (Beni and Esmaeili 2020). As evidenced by Tables 3 and 4, the adsorption behavior of a variety of pollutants, including organics and heavy metals, has been fitted with the Langmuir model. Chu et al. studied the adsorption of $\mathrm{Cr}$ on bean dreg-derived $\mathrm{N}$-doped activated carbons at different initial concentrations ranging from 0.5 to $8 \mathrm{mmol} / \mathrm{L}$. The corresponding correlation coefficient, $\mathrm{R}^{2}$, was found to be higher for the Langmuir model (0.992) than the Freundlich model (0.843) (Chu et al. 2020). Similar results were obtained by Gai et al., who studied $\mathrm{Cu}$ ion adsorption on $\mathrm{N}$-doped biochar (Gai et al. 2016). Langmuir model provided a better fit for adsorption of $\mathrm{Cd}, \mathrm{Pb}$, and $\mathrm{Zn}$ ions as well on $\mathrm{N}$-doped biochars (Yuan et al. 2018b; Guo et al. 2020). Apart from heavy metals, the adsorption of sulfamethazine and chloramphenicol is also better explained by the Langmuir model on shrimp shellderived biochar (Qin et al. 2016).

Freundlich isotherm is another commonly used model to evaluate adsorbent performance, which, unlike the Langmuir model, assumes multilayer adsorption on the heterogeneous adsorbent surface (Beni and Esmaeili 2020). Adsorption characteristics of several dyes are well described by the Freundlich model. Lian et al. reported adsorption of acid orange 7 and methylene blue on corn straw derived biochar modified by ammonia gas to be better explained by the Freundlich model (Lian et al. 2016). The adsorption of acid red 18 on a wetland plant-based biochar also yielded similar results (Wang et al. 2018). Yang et al. studied the removal of atrazine using wheat straw-derived biochar and reported that the Freundlich model provided a better fit for the experimental data (Yang et al. 2017). Apart from organic pollutants, the adsorption properties of $\mathrm{Cu}$ and $\mathrm{Cd}$ on $\mathrm{N}$-doped 
biochars were also well described with the Freundlich model (Yu et al. 2018).

Other isotherm models were also used to study the adsorptive properties of $\mathrm{N}$-doped biochars. Removal of $\mathrm{Cr}$ using N, P-codoped biochar showed a better fit towards the Sips model over Langmuir and Freundlich isotherms (Chen et al. 2018b). Mood et al. fitted phosphate removal data by fiber derived char on four isotherm models. The $\mathrm{R}^{2}$ values suggested that Redlich-Peterson and a combined Langmuir-Freundlich model provided better fit than Langmuir and Freundlich model (Mood et al. 2020). Besides these conventional isotherm models, which describe the solid-liquid interaction, gas-solid interactions are better explained by the deactivation model, which considers the diffusion resistance created by a dense product layer on a solid adsorbent (Suyadal et al. 2000; Park et al. 2007). The adsorption of $\mathrm{CO}_{2}$ and $\mathrm{SO}_{2}$ on $\mathrm{N}$-doped carbon was fitted with a deactivation model, and corresponding adsorption capacities were calculated (Zhang et al. 2014; Shao et al. 2018).

\subsection{Adsorption kinetics}

It is well known that the adsorption of a solute on adsorbent in a solid-liquid system involves several steps, which include(1) transfer of solutes from the bulk to the adsorbent surface; (2) diffusion of solute molecules through the boundary layer to the adsorbent surface and from the adsorbent surface to its interior pores;(3) inter ac tion of solute molecules with active sites. Adsorption kinetics provides valuable information about these processes and the physical and chemical characteristics of the adsorbent (Tan et al. 2015; Tan and Hameed 2017). Thus, adsorption kinetics helps determine the adsorption mechanism, which may involve the mass transfer and chemical reactions (Kołodyńska et al. 2012; Boutsika et al. 2014). Several mathematical models, such as pseudo-first-order (PFO), pseudosecond-order (PSO), intraparticle diffusion (IPD), and the Elovich model, have been developed to evaluate adsorption kinetics. The equations for these models are given below (Inyang et al. 2016):

$$
\begin{aligned}
& \text { PFO : } q_{t}=q_{e}\left(1-e^{-k_{1} t}\right) \\
& \text { PSO : } q_{t}=\frac{k_{2} q_{e}{ }^{2} t}{1+k_{2} q_{e} t} \\
& \text { Elovich : } q_{t}=\frac{1}{\beta} \ln (\alpha \beta t+1) \\
& \text { IPD : } q_{t}=K_{1} \sqrt{t}+c
\end{aligned}
$$

PFO and PSO are the most commonly used models to fit adsorption data by $\mathrm{N}$-doped biochars. The PFO model is the simplest and earliest form of all adsorption kinetic models, which describes the rate of adsorption in liquid-phase systems. PSO models are used when a chemical reaction is involved between adsorbate and adsorbent. Although the present adsorptive studies with $\mathrm{N}$-doped biochars evaluate both PFO and PSO to fit the data, the data are explained better by the PSO model, as seen in Tables 3 and 4. According to Gupta and Bhattacharya (Sen Gupta and Bhattacharyya 2011), PFO may apply on the initial 20-30 min of the adsorption process, after which the model might not fit the entire range of adsorption data. The PSO model's prevalence in various adsorption studies (Tables 3 and 4 ) reiterates the importance of surface functionalities on N-doped biochar in pollutant removal. Most of the studies involving adsorption characteristics of $\mathrm{N}$-doped biochar considered reactionbased kinetics to explain the phenomena, probably due to the prevalence of the interaction between nitrogen-surface functionality and the contaminants. However, the reactionbased kinetic models alone do not necessarily capture the complete picture of adsorption kinetics as the particle diffusion process, which has an important effect on adsorption kinetics, is out of consideration (Kumar and Gaur 2011). Thus, there is a dearth of literature focusing on the diffusion kinetics of adsorption processes by $\mathrm{N}$-doped biochars, and future studies are suggested on this topic.

\subsection{Adsorption thermodynamics}

Thermodynamics plays a vital role in elucidating the underlying mechanisms of adsorption processes. The thermodynamic parameters such as enthalpy change, $\Delta H^{\mathrm{o}}$; entropy change, $\Delta S^{\mathrm{o}}$; and change in Gibbs free energy, $\Delta G^{\mathrm{o}}$ can be derived from the isotherm model constants, which explain the relation between the thermodynamic properties of the adsorption system and the isotherms (Inyang et al. 2016). These parameters can be estimated with the following equations:

$K_{e}=\frac{q_{e}}{C_{e}}$

$\Delta G^{o}=-R T \ln K_{e}$

$\Delta G^{o}=\Delta H^{o}-T \Delta S^{o}$

$\ln K_{e}=\frac{\Delta S^{o}}{R}-\frac{\Delta H^{o}}{R}$

where, $K_{e}(1 / \mathrm{g})$ is the adsorption equilibrium constant, $R(\mathrm{~J} /$ mol $\mathrm{K})$ is the universal gas constant, and $T(\mathrm{~K})$ is the absolute temperature. 
Apart from endothermicity (enthalpy positive, increase in adsorption with an increase in temperature) and exothermicity (enthalpy negative, decrease in adsorption with increase in temperature) of the adsorption processes, these thermodynamic parameters can provide additional insights into the molecular level phenomena of the adsorption systems. For example, a change in the absolute value of enthalpy greater than $100 \mathrm{~kJ} / \mathrm{mol}$ suggests covalent bonds forming through chemisorption (Tong et al. 2019). Similarly, free energy change can also distinguish physisorption ( -20 to $0 \mathrm{~kJ} / \mathrm{mol}$ ) or chemisorption ( -400 to $-80 \mathrm{~kJ} / \mathrm{mol}$ ) (Inyang et al. 2016). However, a few adsorption studies involving $\mathrm{N}$-doped biochars reported thermodynamic characteristics of the adsorption process, which are summarized in Tables 3 and 4. For example, Chen et al. reported endothermic adsorption of $\mathrm{Cr}(\mathrm{VI})$ on N-doped biochar (Chen et al. 2018b). Similarly, the adsorption of bisphenol A on $U$. prolifera based N-doped biochar was also endothermic (Lu et al. 2017). An adsorbate requires energy to break hydrogen bonds for diffusion through water and to replace the pre-adsorbed water molecules on the adsorbent. Energy is needed for the diffusion of adsorbates inside the adsorbent's porous network as well (Tong et al. 2019). Supplying external energy might facilitate these processes, and the adsorption capacity increases with temperature. However, additional research is needed to ascertain this.

\section{Effect of experimental parameters on the adsorption}

\subsection{Effect of solution pH}

The solution $\mathrm{pH}$ is an essential parameter for optimizing the adsorption processes. Along with the surface charge of adsorbents, it also affects the degree of ionization and the speciation of adsorbates (Regmi et al. 2012; Zhang et al. 2013; Tan et al. 2015). Consequently, $\mathrm{pH}$ is one of the most studied parameters for evaluating the adsorptive properties of N-doped biochars.

An important $\mathrm{pH}$-dependent surface property of biochars is the point of zero charge (PZC) which can be defined as the $\mathrm{pH}$ of the solution at which the net surface charge of the adsorbent is zero (Mahmood et al. 2011). When the solution $\mathrm{pH}$ is lower than the PZC of the adsorbent ( $\mathrm{pH}<\mathrm{PZC}$ ), the surface of the biochars becomes positively charged owing to a protonation reaction. This condition is favorable for the electrostatic attraction of anions (He and $\mathrm{Hu} 2012$ ). Whereas, at $\mathrm{pH}>\mathrm{PZC}$, the active adsorption sites on biochar surface deprotonated, rendering a negative biochar surface which is favorable for cation adsorption.

Thus, it is observed that when $\mathrm{pH}<\mathrm{PZC}$, with an increase in solution $\mathrm{pH}$, the adsorption capacity for cations increases. Yin et al. studied the adsorption of $\mathrm{Ni}$ and 2,4DCP on N-doped biochar prepared with Trapa natans husks and shrimp or crab bran at various $\mathrm{pH}$ levels and reported that with increasing $\mathrm{pH}$, the adsorption capacity decreased for 2,4-DCP, and increased for Ni (Yin et al. 2019). This is because at lower $\mathrm{pH}$ values, the surface of $\mathrm{N}$-doped biochar was positively charged, and 2,4 DCP was neutral, which favored their electrostatic attraction. Conversely, for $\mathrm{Ni}$ at lower $\mathrm{pH}$, electrostatic repulsion between positive metal ions and the protonated surface of $\mathrm{N}$-doped biochar hindered the adsorption. Moreover, cations likely compete with the $\mathrm{H}^{+}$ions at lower $\mathrm{pH}$ values for adsorption sites. As the $\mathrm{pH}$ increases, this competition becomes less significant (Gai et al. 2016). Also, the ionization degree of 2,4 DCP, and consequently 2,4-DCP anions, increased with the solution $\mathrm{pH}$. The surface of the modified biochar became negatively charged at higher $\mathrm{pH}$, and the electrostatic repulsion further reduced the adsorption of 2,4-DCP (Yin et al. 2019). For the same reason, the adsorption of anionic dye, acid orange 7, was favored on $\mathrm{N}$-doped biochars having PZC $>10.0$ as reported by Lian et al. (2016). Similarly, Macchi et al. reported that the adsorption of methylene blue, a cationic dye, was favored at a $\mathrm{pH}$ greater than the $\mathrm{PZC}$ of $\mathrm{N}$-doped biochar (Macchi et al. 2020). Also, $\mathrm{Cr}(\mathrm{VI})$ exists as oxyanion $\left(\mathrm{CrO}_{4}{ }^{2-}, \mathrm{Cr}_{2} \mathrm{O}_{7}{ }^{2-}, \mathrm{HCrO}_{4}{ }^{-}\right)$in solutions of high as well as low $\mathrm{pH}$. Hence, a low solution $\mathrm{pH}$ is favorable for its adsorption (Guo et al. 2019; Chu et al. 2020).

\subsection{Effect of co-existing chemicals}

Industrial wastewaters seldom entirely consist of one pollutant but multiple chemical species. Therefore, to evaluate the selectivity of $\mathrm{N}$-doped biochar adsorbents towards the pollutant of interest, it is necessary to carry out adsorption tests in the presence of multiple chemical species. Yang et al. studied the adsorption of $\mathrm{Cu}$ ions with amino-modified biochar in the presence of calcium, potassium, and magnesium ions (Yang and Jiang 2014). Divalent ions adversely affected the $\mathrm{Cu}$ uptake capacity more than the monovalent ions. Among the divalent ions, the presence of magnesium ions was less influential than calcium ions in $\mathrm{Cu}$ adsorption probably because $\mathrm{Mg}(\mathrm{OH})_{2}$ is more stable, and the higher covalent nature of magnesium ions leads to direct dehydration, and thus, its interaction with active sites reduced. According to $\mathrm{Lu}$ et al., the adsorption capacity of U. prolifera based $\mathrm{N}$-doped biochar towards bisphenol A almost doubled when the ionic strength increased from 0 to $50 \mathrm{mM}$ (Lu et al. 2017). However, the authors also reported that the adsorption capacity decreased from 33.14 to $27.83 \mathrm{mg} / \mathrm{g}$ when the ionic strength increased from 0 to $5 \mathrm{mM}$. The increase in salt concentration might have decreased the solubility of bisphenol A resulting in better adsorption performance. On the other hand, Zheng et al. reported a 
decrease in the removal performance of methyl orange by $\mathrm{MgO} / \mathrm{N}$-doped biochar in the presence of inorganic ions such as $\mathrm{Na}_{2} \mathrm{SO}_{4}, \mathrm{NaCl}, \mathrm{Na}_{2} \mathrm{CO}_{3}$, and $\mathrm{NaH}_{2} \mathrm{PO}_{4}$ (Zheng et al. 2020). The authors argued that co-existing ions could have altered the solution's $\mathrm{pH}$, weakening the electrostatic attraction between methyl orange and adsorbent. Moreover, the anions also competed for adsorption with methyl orange. Therefore, it can be inferred based on current knowledge that $\mathrm{N}$-doped biochar's adsorption performance in the presence of other chemical species towards a particular contaminant is highly situation-specific and cannot be generalized. Thus, further studies are required to understand the selectivity of $\mathrm{N}$-doped biochars better.

\section{Reusability of N-doped biochars}

Reusability is a highly desired property of an optimum adsorbent. The economic success of industrial adsorption operation depends on the adsorbents' reusability even after several cycles of performance. The two principles of adsorbent regeneration are adsorbate desorption and adsorbate degradation (Dai et al. 2019). Lian et al. used both the principles to regenerate $\mathrm{N}$-doped biochar after acid orange 7 adsorption (Lian et al. 2016). The authors heated the spent adsorbent at $300{ }^{\circ} \mathrm{C}$ for $1 \mathrm{~h}$ for regeneration, and about $65 \%$ of the original adsorption capacity of $\mathrm{N}$-doped biochar was retained after five cycles of adsorption/heating. For regeneration through desorption, the authors stirred the adsorbent in $60 \%$ ethanol for $12 \mathrm{~h}$ and reported that $60 \%$ of the original adsorption capacity was retained after five adsorption/desorption cycles. Similarly, after methylene blue adsorption, Hu et al. (2019) regenerated the spent N-doped biochar by washing it in distilled water and ethanol. Although $>95 \%$ of methylene blue could be removed after adding PMS over five cycles, the degradation rate decreased due to blockage of active sites by organic compounds and partial oxidation of the adsorbent under a highly oxidizing environment. The authors also studied the catalytic adsorption performance of the spent adsorbent after heat treatment at $400{ }^{\circ} \mathrm{C}$ for $2 \mathrm{~h}$ and reported a better degradation rate of methylene blue than the ethanol regenerated sample. Yuan et al. used diluted $\mathrm{HNO}_{3}$ solution to regenerate $\mathrm{N}$-doped carbon after $\mathrm{Pb}$ adsorption (Yuan et al. 2018b). The authors reported good reusability of the material as the removal efficiency of the $\mathrm{Pb}$ ions was maintained as the fresh one after the fifth cycle, indicating that the active sites could be fully regenerated by the acidtreatment process. Thermal regeneration of adsorbents using microwave radiation is also gaining attention. Although this technique has not been used for the regeneration of N-doped biochar, Foo and Hameed employed the microwave regeneration technique for spent activated carbons and reported that the microwave-assisted regeneration process requires less time with more manageable heat controlling and no thermal inertia effect (Foo and Hameed 2012). Moreover, it requires less energy and reduces the risk of secondary pollution. Although the literature involving recyclability evaluation of $\mathrm{N}$-doped biochar is scarce, it can be inferred that $\mathrm{N}$-doped biochars can potentially be designed to possess good recyclability and thermal stability based on the reported studies. However, further research is needed to validate these ideas.

\section{Conclusion and future prospects}

In the present review, we summarized the various preparation processes of $\mathrm{N}$-doped biochar for aqueous adsorption processes. The structure of $\mathrm{N}$-doped biochar consists of oxygen as well as nitrogen functional groups. Among nitrogen surface functionalities, pyrrolic-N, pyridinic-N, and graphitic- $\mathrm{N}$ are prevalent. These surface functionalities are critical to the adsorptive properties of N-doped biochars toward heavy metals and organics. The adsorption mechanisms for heavy metals include ion exchange, precipitation, complexation, electrostatic interaction, and cation-pi bonding, whereas, for organic contaminants, the mechanisms include pore filling, H-bonding, $\pi-\pi$ EDA interactions, electrostatic interaction, and Lewis acid-base interactions. Further research is necessary to gain insight into the mechanistic aspects of adsorption, regeneration, and selectivity of $\mathrm{N}$-doped biochars. Based on the aforementioned discussions on $\mathrm{N}$-doped biochars and considering their favorable chemistry, it can be inferred that $\mathrm{N}$-doped biochars have the potential to serve as lowcost adsorbents for wastewater treatment. As the research in this field is still emerging, scientists are presented with several exciting opportunities to move the research forward.

The process of N-doping on biochar surfaces typically results in the formation of various types of nitrogen functionalities, including pyridinic-N, pyrrolic- $\mathrm{N}$, amino-N, graphitic-N, oxidized-N, and others. However, for specific adsorption processes such as adsorption of anionic species, graphitic type nitrogen species are ideal due to their positive charge (Zhu et al. 2020b). Similarly, for the adsorption of $\mathrm{CO}_{2}$, amine and azo groups might enhance the adsorptive performance (Zhang et al. 2017). Therefore, to enhance N-doped biochars' applicability as selective adsorbents, systematic efforts are needed to develop protocols to synthesize targeted species of nitrogen on biochar surfaces. Understanding the mechanism of $\mathrm{N}$-doping will significantly aid in designing effective application-specific $\mathrm{N}$-doped biochar fabrication strategies. Quantum chemical packages with DFT calculations might assist in addressing these mechanism-related problems. There are already a number of published studies that elucidate the doping 
mechanism through computational modeling of $\mathrm{N}$-doped graphene that is in agreement with the experimental data (Zhang and Xia 2011; Li et al. 2016; Wang et al. 2016). Similar computational approaches can be employed to rationally design $\mathrm{N}$-biochars in light of the target molecule's chemistry.

Furthermore, the choice of raw materials (biomass or $\mathrm{N}$-dopant, or both) affects the overall properties of biochar in addition to the individual nitrogen speciation. Kasera et al. recently reported that when an equal amount of nitrogen from different precursor chemicals (melamine, urea, ammonium chloride, and ammonium nitrate) was used to dope pine bark biochars, melamine modified biochar had the highest amount of nitrogen, and urea modified biochar showed the highest percentage of graphitic-N (Kasera et al. 2021). Therefore, fundamental studies focused on the precursor-surface chemistry relationships are needed for optimizing the engineering design of $\mathrm{N}$-doped biochars.

$\mathrm{N}$-doped biochars' applicability can be extended towards the removal of unregulated organic emerging contaminants (ECs), which consist of pesticides, personal care products, pharmaceuticals, and others. These ECs are commonly found in water as a result of municipal discharge, posing a severe threat to the aquatic environment as well as human health (Tan et al. 2016). For practical engineering applications, attention should be focused on the adsorption studies of target contaminants from real-world waste streams. In laboratory settings, removal properties of simulated solutions of a single contaminant are often reported. However, real-world wastewaters typically consist of multiple contaminants that co-exist. Thus, the focus should be directed towards achieving selectivity towards target contaminants by $\mathrm{N}$-doped biochars. Future studies should also focus on using $\mathrm{N}$-doped biochar for treating actual industrial wastewater.

Computational approaches can also provide insights into how these N-doped biochars perform when subjected to multiple contaminants simultaneously. Eco-friendly, effective, and economic regeneration of $\mathrm{N}$-doped biochar is another vital issue to be addressed for making the adsorption process economically feasible. Comprehensive studies on economic and life-cycle analysis of $\mathrm{N}$-doped biochars are needed. For scaling up an adsorption process, it is imperative to obtain data from continuous column experiments. Few, if any, studies have focused on continuous adsorption experiments with $\mathrm{N}$-doped biochars to remove either organics or heavy metals. Thus, future studies focusing on flowthrough adsorption columns are also needed.

Supplementary Information The online version contains supplementary material available at https://doi.org/10.1007/s42773-022-00145-2.

Acknowledgements The authors would like to thank Dr. Garey Fox and Dr. Khandoker Samaher Salem for reviewing the manuscript and providing constructive insights.
Authors' contributions NK: Conceptualization, Literature search, Literature review, Writing - original draft preparation, and revision. SH: Supervision, Funding acquisition, Writing-Review and editing. PK: Conceptualization, Supervision, Writing-Review and editing. All authors read and approved the final manuscript.

Authors' information Nitesh Kasera (Google Scholar Profile-Kasera) Ph.D. Candidate, Dept. of Biological and Agricultural Engineering, North Carolina State University. Dr. Steven Hall (Google Scholar Profile-Hall) Associate Professor, Dept. of Biological and Agricultural Engineering, North Carolina State University. Director, Marine Aquaculture Research Center, North Carolina State University. Dr. Praveen Kolar (Google Scholar Profile-Kolar) Professor-Agricultural Waste Management, Dept. of Biological and Agricultural Engineering, North Carolina State University.

Funding This research was funded by North Carolina State University College of Agricultural and Life Sciences Biological and Agricultural Engineering and William White Endowment of the North Carolina Agriculture Foundation.

Availability of data and materials Data sharing not applicable to this article as no datasets were generated or analysed during the current study.

\section{Declarations}

Competing interests The authors declare that they have no known competing financial interests or personal relationships that could have appeared to influence the work reported in this paper.

Ethics approval and consent to participate Not applicable.

Consent for publication Not applicable.

Open Access This article is licensed under a Creative Commons Attribution 4.0 International License, which permits use, sharing, adaptation, distribution and reproduction in any medium or format, as long as you give appropriate credit to the original author(s) and the source, provide a link to the Creative Commons licence, and indicate if changes were made. The images or other third party material in this article are included in the article's Creative Commons licence, unless indicated otherwise in a credit line to the material. If material is not included in the article's Creative Commons licence and your intended use is not permitted by statutory regulation or exceeds the permitted use, you will need to obtain permission directly from the copyright holder. To view a copy of this licence, visit http://creativecommons.org/licenses/by/4.0/.

\section{References}

Abbas Z, Ali S, Rizwan M et al (2018) A critical review of mechanisms involved in the adsorption of organic and inorganic contaminants through biochar. Arab J Geosci. https://doi.org/10.1007/ s12517-018-3790-1

Al-Abachi MQ, Al-Awady NSA-A, Al-Anbakey AM (2013) Evaluation of poly acrylic acid(PAA) hydrogel beads as adsorbent for the removal of lead(II)ion from water. J Al-Nahrain Univ Sci 16:30-39. https://doi.org/10.22401/jnus.16.3.04 
Ali I, Gupta VK (2007) Advances in water treatment by adsorption technology. Nat Protoc 1:2661-2667. https://doi.org/10.1038/ nprot.2006.370

Ali ZA, Venkatesan J, Kim SK, Sudha PN (2011) Beneficial effect of chitosan-g-polyacrylamide copolymer in removal of heavy metals from industrial dye effluents. Int J Environ Sci 1:820-833

Ali S, Rizwan M, Qayyum MF et al (2017) Biochar soil amendment on alleviation of drought and salt stress in plants: a critical review. Environ Sci Pollut Res 24:12700-12712. https://doi.org/10.1007/ s11356-017-8904-X

Ayawei N, Ebelegi AN, Wankasi D (2017) Modelling and interpretation of adsorption isotherms. J Chem. https://doi.org/10.1155/ 2017/3039817

Beni AA, Esmaeili A (2020) Biosorption, an efficient method for removing heavy metals from industrial effluents: a review. Environ Technol Innov 17:100503. https://doi.org/10.1016/j.eti.2019. 100503

Biswal M, Banerjee A, Deo M, Ogale S (2013) From dead leaves to high energy density supercapacitors. Energy Environ Sci 6:12491259. https://doi.org/10.1039/c3ee22325f

Borghei M, Laocharoen N, Kibena-Põldsepp E et al (2017) Porous N, P-doped carbon from coconut shells with high electrocatalytic activity for oxygen reduction: alternative to $\mathrm{Pt}-\mathrm{C}$ for alkaline fuel cells. Appl Catal B 204:394-402. https://doi.org/10.1016/j. apcatb.2016.11.029

Boutsika LG, Karapanagioti HK, Manariotis ID (2014) Aqueous mercury sorption by biochar from malt spent rootlets. Water Air Soil Pollut. https://doi.org/10.1007/s11270-013-1805-9

Chan KY, Van Zwieten L, Meszaros I et al (2008) Using poultry litter biochars as soil amendments. Aust J Soil Res 46:437-444

Chen W, Yang H, Chen Y et al (2016) Biomass pyrolysis for nitrogencontaining liquid chemicals and nitrogen-doped carbon materials. J Anal Appl Pyrol 120:186-193. https://doi.org/10.1016/j. jaap.2016.05.004

Chen SS, Yu IKM, Cho DW et al (2018a) Selective glucose isomerization to fructose via a nitrogen-doped solid base catalyst derived from spent coffee grounds. ACS Sustain Chem Eng 6:1611316120. https://doi.org/10.1021/acssuschemeng.8b02752

Chen S, Wang J, Wu Z et al (2018b) Enhanced Cr(VI) removal by polyethylenimine- and phosphorus-codoped hierarchical porous carbons. J Colloid Interface Sci 523:110-120. https://doi.org/10. 1016/j.jcis.2018.03.057

Chen W, Chen Y, Yang H et al (2018c) Investigation on biomass nitrogen-enriched pyrolysis: influence of temperature. Bioresour Technol 249:247-253. https://doi.org/10.1016/j.biortech. 2017.10.022

Chen W, Fang Y, Li K et al (2020) Bamboo wastes catalytic pyrolysis with N-doped biochar catalyst for phenols products. Appl Energy 260:114242. https://doi.org/10.1016/j.apenergy.2019.114242

Cheng N, Wang B, Wu P et al (2021) Adsorption of emerging contaminants from water and wastewater by modified biochar: a review. Environ Pollut 273:116448. https://doi.org/10.1016/j.envpol. 2021.116448

Chu B, Amano Y, Machida M (2020) Preparation of bean dreg derived $\mathrm{N}$-doped activated carbon with high adsorption for $\mathrm{Cr}(\mathrm{VI})$. Colloids Surf A 586:124262. https://doi.org/10.1016/j.colsurfa.2019. 124262

Crabtree RH (2009) The organometallic chemistry of the transition metals. Wiley, Hoboken

Dai Y, Zhang N, Xing C et al (2019) The adsorption, regeneration and engineering applications of biochar for removal organic pollutants: a review. Chemosphere 223:12-27. https://doi.org/10. 1016/j.chemosphere.2019.01.161

Dreyer JAH, Li P, Zhang L et al (2017) Influence of the oxide support reducibility on the $\mathrm{CO}_{2}$ methanation over Ru-based catalysts.
Appl Catal B 219:715-726. https://doi.org/10.1016/j.apcatb. 2017.08.011

Duan X, Sun H, Wang S (2018) Metal-free carbocatalysis in advanced oxidation reactions. Acc Chem Res 51:678-687. https://doi.org/ 10.1021/acs.accounts.7b00535

Ehsani A, Parsimehr H (2020) Electrochemical energy storage electrodes from fruit biochar. Adv Colloid Interface Sci 284:102263. https://doi.org/10.1016/j.cis.2020.102263

El-Khaiary MI (2008) Least-squares regression of adsorption equilibrium data: comparing the options. J Hazard Mater 158:73-87. https://doi.org/10.1016/j.jhazmat.2008.01.052

Foo KY, Hameed BH (2012) Microwave-assisted regeneration of activated carbon. Bioresour Technol 119:41-47. https://doi.org/10. 1016/j.biortech.2012.05.061

Fowles M (2007) Black carbon sequestration as an alternative to bioenergy. Biomass Bioenergy 31:426-432. https://doi.org/10.1016/j. biombioe.2007.01.012

Gai C, Guo Y, Peng N et al (2016) N-doped biochar derived from cohydrothermal carbonization of rice husk and: Chlorella pyrenoidosa for enhancing copper ion adsorption. RSC Adv 6:5371353722. https://doi.org/10.1039/c6ra09270e

Gao Y, Xu S, Yue Q et al (2016) Synthesis and characterization of heteroatom-enriched biochar from keratin-based and algous-based wastes. Adv Powder Technol 27:1280-1286. https://doi.org/10. 1016/j.apt.2016.04.018

Guo H, Jiao T, Zhang Q et al (2015) Preparation of graphene oxidebased hydrogels as efficient dye adsorbents for wastewater treatment. Nanoscale Res Lett. https://doi.org/10.1186/ s11671-015-0931-2

Guo S, Gao Y, Wang Y et al (2019) Urea/ $\mathrm{ZnCl}_{2}$ in situ hydrothermal carbonization of Camellia sinensis waste to prepare N-doped biochar for heavy metal removal. Environ Sci Pollut Res 26:3036530373. https://doi.org/10.1007/s11356-019-06194-8

Guo S, Wang Y, Wei X et al (2020) Structural analysis and heavy metal adsorption of $\mathrm{N}$-doped biochar from hydrothermal carbonization of Camellia sinensis waste. Environ Sci Pollut Res 27:18866-18874. https://doi.org/10.1007/s11356-020-08455-3

Han J, Zhang L, Zhao B et al (2019) The N-doped activated carbon derived from sugarcane bagasse for $\mathrm{CO}_{2}$ adsorption. Ind Crops Prod 128:290-297. https://doi.org/10.1016/j.indcrop.2018.11. 028

Hao F, Zhao X, Ouyang W et al (2013) Molecular structure of corncobderived biochars and the mechanism of Atrazine sorption. Agron J 105:773-782. https://doi.org/10.2134/agronj2012.0311

$\mathrm{He} \mathrm{C,} \mathrm{Hu} \mathrm{X} \mathrm{(2012)} \mathrm{Functionalized} \mathrm{ordered} \mathrm{mesoporous} \mathrm{carbon} \mathrm{for} \mathrm{the}$ adsorption of reactive dyes. Adsorption 18:337-348. https://doi. org/10.1007/s10450-012-9410-6

Ho SH, di Chen Y, Li R et al (2019) N-doped graphitic biochars from C-phycocyanin extracted Spirulina residue for catalytic persulfate activation toward nonradical disinfection and organic oxidation. Water Res 159:77-86. https://doi.org/10.1016/j.watres. 2019.05.008

Hou J, Jiang T, Wei R et al (2019) Ultrathin-layer structure of BiOI microspheres decorated on $\mathrm{N}$-doped biochar with efficient photocatalytic activity. Front Chem 7:1-10. https://doi.org/10.3389/ fchem.2019.00378

$\mathrm{Hu}$ W, Xie Y, Lu S et al (2019) One-step synthesis of nitrogen-doped sludge carbon as a bifunctional material for the adsorption and catalytic oxidation of organic pollutants. Sci Total Environ 680:51-60. https://doi.org/10.1016/j.scitotenv.2019.05.098

Huggins TM, Pietron JJ, Wang $\mathrm{H}$ et al (2015) Graphitic biochar as a cathode electrocatalyst support for microbial fuel cells. Bioresour Technol 195:147-153. https://doi.org/10.1016/j.biortech.2015. 06.012 
Iavicoli I, Fontana L, Bergamaschi A (2009) The effects of metals as endocrine disruptors. J Toxicol Environ Health B 12:206-223. https://doi.org/10.1080/10937400902902062

Inyang M, Gao B, Pullammanappallil P et al (2010) Biochar from anaerobically digested sugarcane bagasse. Bioresour Technol 101:8868-8872. https://doi.org/10.1016/j.biortech.2010.06.088

Inyang MI, Gao B, Yao Y et al (2016) A review of biochar as a low-cost adsorbent for aqueous heavy metal removal. Crit Rev Environ Sci Technol 46:406-433. https://doi.org/10.1080/10643389. 2015.1096880

Jiang Q, Xie W, Han S et al (2019) Enhanced adsorption of Pb(II) onto modified hydrochar by polyethyleneimine or $\mathrm{H}_{3} \mathrm{PO}_{4}$ : an analysis of surface property and interface mechanism. Colloids Surf A 583:123962. https://doi.org/10.1016/j.colsurfa.2019.123962

Jin Z, Wang B, Ma L et al (2020) Air pre-oxidation induced high yield $\mathrm{N}$-doped porous biochar for improving toluene adsorption. Chem Eng J 385:123843. https://doi.org/10.1016/j.cej.2019.123843

Kasera N, Hall S, Kolar P (2021) Effect of surface modification by nitrogen-containing chemicals on morphology and surface characteristics of N-doped pine bark biochars. J Environ Chem Eng 9:105161. https://doi.org/10.1016/j.jece.2021.105161

Kasnejad MH, Esfandiari A, Kaghazchi T, Asasian N (2012) Effect of pre-oxidation for introduction of nitrogen containing functional groups into the structure of activated carbons and its influence on $\mathrm{Cu}$ (II) adsorption. J Taiwan Inst Chem Eng 43:736-740. https:// doi.org/10.1016/j.jtice.2012.02.006

Kołodyńska D, Wnetrzak R, Leahy JJ et al (2012) Kinetic and adsorptive characterization of biochar in metal ions removal. Chem Eng J 197:295-305. https://doi.org/10.1016/j.cej.2012.05.025

Kumar D, Gaur JP (2011) Chemical reaction- and particle diffusionbased kinetic modeling of metal biosorption by a Phormidium sp.-dominated cyanobacterial mat. Bioresour Technol 102:633640. https://doi.org/10.1016/j.biortech.2010.08.014

Kurt S (2010) Review of the stability of biochar in soils: predictability of O:C molar rations. Carbon Manag 1:289-303

Lam SS, Chase HA (2012) A review on waste to energy processes using microwave pyrolysis. Energies 5:4209-4232. https://doi. org/10.3390/en5104209

Lee KJ, Miyawaki J, Shiratori N et al (2013) Toward an effective adsorbent for polar pollutants: formaldehyde adsorption by activated carbon. J Hazard Mater 260:82-88. https://doi.org/10.1016/j. jhazmat.2013.04.049

Leng L, Xu S, Liu R et al (2019) Nitrogen containing functional groups of biochar: an overview. Bioresour Technol 298:122286. https:// doi.org/10.1016/j.biortech.2019.122286

Li Z, Zhang L, Amirkhiz BS et al (2012) Carbonized chicken eggshell membranes with $3 \mathrm{D}$ architectures as high-performance electrode materials for supercapacitors. Adv Energy Mater 2:431-437. https://doi.org/10.1002/aenm.201100548

Li XF, Lian KY, Liu L et al (2016) Unraveling the formation mechanism of graphitic nitrogen-doping in thermally treated graphene with ammonia. Sci Rep 6:1-10. https://doi.org/10.1038/srep2 3495

Li R, Wang JJ, Zhou B et al (2017) Simultaneous capture removal of phosphate, ammonium and organic substances by $\mathrm{MgO}$ impregnated biochar and its potential use in swine wastewater treatment. J Clean Prod 147:96-107. https://doi.org/10.1016/j.jclep ro.2017.01.069

Li Y, Xing B, Wang X et al (2019) Nitrogen-doped hierarchical porous biochar derived from corn stalks for phenol-enhanced adsorption. Energy Fuels 33:12459-12468. https://doi.org/10.1021/acs.energ yfuels.9b02924

Li D, Chen W, Wu J et al (2020) The preparation of waste biomass-derived $\mathrm{N}$-doped carbons and their application in acid gas removal: focus on $\mathrm{N}$ functional groups. J Mater Chem A 8:24977-24995. https://doi.org/10.1039/d0ta07977d

Lian F, Cui G, Liu Z et al (2016) One-step synthesis of a novel N-doped microporous biochar derived from crop straws with high dye adsorption capacity. J Environ Manag 176:61-68. https://doi.org/ 10.1016/j.jenvman.2016.03.043

Liang J, Tang D, Huang L et al (2018) High oxygen reduction reaction performance nitrogen-doped biochar cathode: a strategy for comprehensive utilizing nitrogen and carbon in water hyacinth. Bioresour Technol 267:524-531. https://doi.org/10.1016/j.biort ech.2018.07.085

Ling LL, Liu WJ, Zhang S, Jiang H (2017) Magnesium oxide embedded nitrogen self-doped biochar composites: fast and highefficiency adsorption of heavy metals in an aqueous solution. Environ Sci Technol 51:10081-10089. https://doi.org/10.1021/ acs.est.7b02382

Liu Z, Zhang FS (2009) Removal of lead from water using biochars prepared from hydrothermal liquefaction of biomass. J Hazard Mater 167:933-939. https://doi.org/10.1016/j.jhazmat.2009.01. 085

Liu F, Peng H, You C et al (2014) High-performance doped carbon catalyst derived from nori biomass with melamine promoter. Electrochim Acta 138:353-359. https://doi.org/10.1016/j.elect acta.2014.06.098

Liu WJ, Jiang H, Yu HQ (2015) Development of biochar-based functional materials: toward a sustainable platform carbon material. Chem Rev 115:12251-12285. https://doi.org/10.1021/acs.chemr ev.5b00195

Liu L, Tan Z, Ye Z (2018) Transformation and transport mechanism of nitrogenous compounds in a biochar "Preparation-Returning to the Field" process studied by employing an isotope tracer method. ACS Sustain Chem Eng 6:1780-1791. https://doi.org/ 10.1021/acssuschemeng.7b03172

Liu WJ, Jiang H, Yu HQ (2019) Emerging applications of biocharbased materials for energy storage and conversion. Energy Environ Sci 12:1751-1779. https://doi.org/10.1039/c9ee00206e

Liu YX, Du SM, Cao J et al (2020) Simultaneous determination of hydroquinone and catechol by $\mathrm{N}$-doped porous biochar-modified electrode. Bull Korean Chem Soc 41:261-265. https://doi.org/ 10.1002/bkcs. 11954

Lorenc-Grabowska E, Diez MA, Gryglewicz G (2016) Influence of pore size distribution on the adsorption of phenol on PET-based activated carbons. J Colloid Interface Sci 469:205-212. https:// doi.org/10.1016/j.jcis.2016.02.007

Lu J, Zhang C, Wu J, Luo Y (2017) Adsorptive removal of bisphenol A using N-doped biochar made of Ulva prolifera. Water Air Soil Pollut 228:1-9. https://doi.org/10.1007/s11270-017-3516-0

Luo W, Wang B, Heron CG et al (2014) Pyrolysis of cellulose under ammonia leads to nitrogen-doped nanoporous carbon generated through methane formation. Nano Lett 14:2225-2229. https:// doi.org/10.1021/nl500859p

Ma JC, Dougherty DA (1997) The cation- $\pi$ interaction. Chem Rev 97:1303-1324. https://doi.org/10.1021/cr9603744

Macchi S, Siraj N, Viswanathan T (2020) Kinetic and mechanistic study of dye sorption onto renewable resource-based doped carbon prepared by a microwave-assisted method. Environ Technol (united Kingdom). https://doi.org/10.1080/09593330.2020.17452 93

Mahmood T, Saddique MT, Naeem A et al (2011) Comparison of different methods for the point of zero charge determination of NiO. Ind Eng Chem Res 50:10017-10023. https://doi.org/10. 1021/ie200271d

Mecozzi S, West AP, Dougherty DA (1996) Cation $-\pi$ interactions in simple aromatics: electrostatics provide a predictive tool. J Am Chem Soc 118:2307-2308. https://doi.org/10.1021/ja9539608 
Meyer S, Bright RM, Fischer D et al (2012) Albedo impact on the suitability of biochar systems to mitigate global warming. Environ Sci Technol 46:12726-12734. https://doi.org/10.1021/es302302g

Mian Mm, Liu G, Yousaf B et al (2018) simultaneous functionalization and magnetization of biochar via $\mathrm{nh}_{3}$ ambiance pyrolysis for efficient removal of $\mathrm{Cr}(\mathrm{VI})$. Chemosphere 208:712-721. https:// doi.org/10.1016/j.chemosphere.2018.06.021

Mian MM, Liu G, Yousaf B et al (2019) One-step synthesis of N-doped metal/biochar composite using $\mathrm{NH}_{3}$-ambiance pyrolysis for efficient degradation and mineralization of Methylene Blue. J Environ Sci (china) 78:29-41. https://doi.org/10.1016/j.jes.2018.06. 014

Mian MM, Liu G, Zhou H (2020) Preparation of N-doped biochar from sewage sludge and melamine for peroxymonosulfate activation: $\mathrm{N}$-functionality and catalytic mechanisms. Sci Total Environ 744:140862. https://doi.org/10.1016/j.scitotenv.2020.140862

Mohan D, Pittman CU, Bricka M et al (2007) Sorption of arsenic, cadmium, and lead by chars produced from fast pyrolysis of wood and bark during bio-oil production. J Colloid Interface Sci 310:57-73. https://doi.org/10.1016/j.jcis.2007.01.020

Mood SH, Ayiania M, Jefferson-Milan Y, Garcia-Perez M (2020) Nitrogen doped char from anaerobically digested fiber for phosphate removal in aqueous solutions. Chemosphere 240:124889. https://doi.org/10.1016/j.chemosphere.2019.124889

Nguyen TH, Cho HH, Poster DL, Ball WP (2007) Evidence for a porefilling mechanism in the adsorption of aromatic hydrocarbons to a natural wood char. Environ Sci Technol 41:1212-1217. https:// doi.org/10.1021/es0617845

Oh WD, Lisak G, Webster RD et al (2018) Insights into the thermolytic transformation of lignocellulosic biomass waste to redox-active carbocatalyst: durability of surface active sites. Appl Catal B 233:120-129. https://doi.org/10.1016/j.apcatb.2018.03.106

Park SW, Choi BS, Lee JW (2007) Breakthrough data analysis of adsorption of toluene vapor in a fixed-bed of granular activated carbon. Sep Sci Technol 42:2221-2233. https://doi.org/10.1080/ 01496390701444105

Pignatello JJ, Kwon S, Lu Y (2006) Effect of natural organic substances on the surface and adsorptive properties of environmental black carbon (Char): attenuation of surface activity by humic and fulvic acids. Environ Sci Technol 40:7757-7763. https://doi.org/ 10.1021/es061307m

Premarathna KSD, Rajapaksha AU, Sarkar B et al (2019) Biocharbased engineered composites for sorptive decontamination of water: a review. Chem Eng J 372:536-550. https://doi.org/10. 1016/j.cej.2019.04.097

Qambrani NA, Rahman MM, Won S et al (2017) Biochar properties and eco-friendly applications for climate change mitigation, waste management, and wastewater treatment: a review. Renew Sustain Energy Rev 79:255-273. https://doi.org/10.1016/j.rser. 2017.05.057

Qin L, Zhou Z, Dai J et al (2016) Novel N-doped hierarchically porous carbons derived from sustainable shrimp shell for high-performance removal of sulfamethazine and chloramphenicol. J Taiwan Inst Chem Eng 62:228-238. https://doi.org/10.1016/j.jtice.2016. 02.009

Rajapaksha AU, Chen SS, Tsang DCW et al (2016) Engineered/ designer biochar for contaminant removal/immobilization from soil and water: potential and implication of biochar modification. Chemosphere 148:276-291. https://doi.org/10.1016/j.chemo sphere.2016.01.043

Regmi P, Garcia Moscoso JL, Kumar S et al (2012) Removal of copper and cadmium from aqueous solution using switchgrass biochar produced via hydrothermal carbonization process. J Environ Manag 109:61-69. https://doi.org/10.1016/j.jenvman.2012.04. 047
Rizwan M, Ali S, Qayyum MF et al (2016) Mechanisms of biocharmediated alleviation of toxicity of trace elements in plants: a critical review. Environ Sci Pollut Res 23:2230-2248. https:// doi.org/10.1007/s11356-015-5697-7

Sahu O, Singh N (2018) Significance of bioadsorption process on textile industry wastewater. Elsevier Ltd, Amsterdam

Sawant SY, Pawar RR, Lee SM, Cho MH (2017) Binder-free production of 3D N-doped porous carbon cubes for efficient $\mathrm{Pb}^{2+}$ removal through batch and fixed bed adsorption. J Clean Prod 168:290-301. https://doi.org/10.1016/j.jclepro.2017.08.229

Schmidt HP, Kammann C, Niggli C et al (2014) Biochar and biocharcompost as soil amendments to a vineyard soil: influences on plant growth, nutrient uptake, plant health and grape quality. Agr Ecosyst Environ 191:117-123. https://doi.org/10.1016/j. agee.2014.04.001

Sen Gupta S, Bhattacharyya KG (2011) Kinetics of adsorption of metal ions on inorganic materials: a review. Adv Colloid Interface Sci 162:39-58. https://doi.org/10.1016/j.cis.2010.12.004

Seredych M, Hulicova-Jurcakova D, Lu GQ, Bandosz TJ (2008) Surface functional groups of carbons and the effects of their chemical character, density and accessibility to ions on electrochemical performance. Carbon 46:1475-1488. https://doi.org/10.1016/j. carbon.2008.06.027

Shafeeyan MS, Daud WMAW, Houshmand A, Arami-Niya A (2011) Ammonia modification of activated carbon to enhance carbon dioxide adsorption: effect of pre-oxidation. Appl Surf Sci 257:3936-3942. https://doi.org/10.1016/j.apsusc.2010.11.127

Shao J, Zhang J, Zhang X et al (2018) Enhance $\mathrm{SO}_{2}$ adsorption performance of biochar modified by $\mathrm{CO}_{2}$ activation and amine impregnation. Fuel 224:138-146. https://doi.org/10.1016/j. fuel.2018.03.064

Shen W, Fan W (2013) Nitrogen-containing porous carbons: synthesis and application. J Mater Chem A 1:999-1013. https://doi. org/10.1039/c2ta00028h

Singh NB, Nagpal G, Agrawal S, Rachna (2018) Water purification by using adsorbents: a review. Environ Technol Innov 11:187240. https://doi.org/10.1016/j.eti.2018.05.006

Suyadal Y, Erol M, Oğuz H (2000) Deactivation model for the adsorption of trichloroethylene vapor on an activated carbon bed. Ind Eng Chem Res 39:724-730. https://doi.org/10.1021/ ie990612w

Tan KL, Hameed BH (2017) Insight into the adsorption kinetics models for the removal of contaminants from aqueous solutions. J Taiwan Inst Chem Eng 74:25-48. https://doi.org/10. 1016/j.jtice.2017.01.024

Tan X, Liu Y, Zeng G et al (2015) Application of biochar for the removal of pollutants from aqueous solutions. Chemosphere $125: 70-85$

Tan X, Liu Y, Gu Y et al (2016) Biochar-based nano-composites for the decontamination of wastewater: a review. Bioresour Technol 212:318-333. https://doi.org/10.1016/j.biortech.2016.04.093

Tan X, Liu S, Liu Y et al (2017) Biochar as potential sustainable precursors for activated carbon production: multiple applications in environmental protection and energy storage. Bioresour Technol 227:359-372. https://doi.org/10.1016/j.biortech.2016.12.083

Tian Y, Zhang J, Zuo W et al (2013) Nitrogen conversion in relation to $\mathrm{NH}_{3}$ and $\mathrm{HCN}$ during microwave pyrolysis of sewage sludge. Environ Sci Technol 47:3498-3505. https://doi.org/10.1021/ es304248j

Tong Y, McNamara PJ, Mayer BK (2019) Adsorption of organic micropollutants onto biochar: a review of relevant kinetics, mechanisms and equilibrium. Environ Sci: Water Res Technol 5:821-838. https://doi.org/10.1039/c8ew00938d

Van Tran V, Park D, Lee YC (2018) Hydrogel applications for adsorption of contaminants in water and wastewater treatment. 
Environ Sci Pollut Res 25:24569-24599. https://doi.org/10.1007/ s11356-018-2605-y

Wan Z, Li K (2018) Effect of pre-pyrolysis mode on simultaneous introduction of nitrogen/oxygen-containing functional groups into the structure of bagasse-based mesoporous carbon and its influence on $\mathrm{Cu}(\mathrm{II})$ adsorption. Chemosphere 194:370-380. https://doi.org/10.1016/j.chemosphere.2017.11.181

Wan Z, Sun Y, Tsang DCW et al (2020a) Customised fabrication of nitrogen-doped biochar for environmental and energy applications. Chem Eng J. https://doi.org/10.1016/j.cej.2020.126136

Wan Z, Sun Y, Tsang DCW et al (2020b) Sustainable impact of tartaric acid as electron shuttle on hierarchical iron-incorporated biochar. Chem Eng J. https://doi.org/10.1016/j.cej.2020.125138

Wang J, Wang S (2019) Preparation, modification and environmental application of biochar: a review. J Clean Prod 227:1002-1022. https://doi.org/10.1016/j.jclepro.2019.04.282

Wang WW, Dang JS, Zhao X, Nagase S (2016) Formation mechanisms of graphitic-N: oxygen reduction and nitrogen doping of graphene oxides. J Phys Chem C 120:5673-5681. https://doi.org/ 10.1021/acs.jpcc.5b10607

Wang F, Sun H, Ren X, Zhang K (2017) Sorption of naphthalene and its hydroxyl substitutes onto biochars in single-solute and bisolute systems with propranolol as the co-solute. Chem Eng J 326:281-291. https://doi.org/10.1016/j.cej.2017.05.159

Wang L, Yan W, He C et al (2018) Microwave-assisted preparation of nitrogen-doped biochars by ammonium acetate activation for adsorption of acid red 18. Appl Surf Sci 433:222-231. https:// doi.org/10.1016/j.apsusc.2017.10.031

Wang H, Guo W, Liu B et al (2019a) Edge-nitrogenated biochar for efficient peroxydisulfate activation: an electron transfer mechanism. Water Res 160:405-414. https://doi.org/10.1016/j.watres. 2019.05.059

Wang L, Wang Y, Ma F et al (2019b) Mechanisms and reutilization of modified biochar used for removal of heavy metals from wastewater: a review. Sci Total Environ 668:1298-1309. https://doi. org/10.1016/j.scitotenv.2019.03.011

Wang X, Liu Y, Zhu L et al (2019c) Biomass derived N-doped biochar as efficient catalyst supports for $\mathrm{CO}_{2}$ methanation. $\mathrm{J} \mathrm{CO}_{2}$ Util 34:733-741. https://doi.org/10.1016/j.jcou.2019.09.003

Wang X, Feng J, Cai Y et al (2020) Porous biochar modified with polyethyleneimine (PEI) for effective enrichment of U(VI) in aqueous solution. Sci Total Environ 708:134575. https://doi.org/ 10.1016/j.scitotenv.2019.134575

Woolf D, Amonette JE, Street-Perrott FA et al (2010) Sustainable biochar to mitigate global climate change. Nat Commun. https://doi. org/10.1038/ncomms 1053

Wu FC, Tseng RL, Juang RS (2009) Initial behavior of intraparticle diffusion model used in the description of adsorption kinetics. Chem Eng J 153:1-8. https://doi.org/10.1016/j.cej.2009.04.042

Wu D, Song W, Chen L et al (2020) High-performance porous graphene from synergetic nitrogen doping and physical activation for advanced nonradical oxidation. J Hazard Mater 381:1-10. https://doi.org/10.1016/j.jhazmat.2019.121010

Xie Y, Hu W, Wang X et al (2020) Molten salt induced nitrogen-doped biochar nanosheets as highly efficient peroxymonosulfate catalyst for organic pollutant degradation. Environ Pollut 260:114053. https://doi.org/10.1016/j.envpol.2020.114053

Xu X, Cao X, Zhao L et al (2014) Interaction of organic and inorganic fractions of biochar with $\mathrm{Pb}$ (ii) ion: further elucidation of mechanisms for Pb(ii) removal by biochar. RSC Adv 4:44930-44937. https://doi.org/10.1039/c4ra07303g

Xu J, Zhang X, Sun C et al (2018) Catalytic degradation of diatrizoate by persulfate activation with peanut shell biochar-supported nano zero-valent iron in aqueous solution. Int J Environ Res Public Health 15:1-18. https://doi.org/10.3390/ijerph15091937
Xu X, Zheng Y, Gao B, Cao X (2019) N-doped biochar synthesized by a facile ball-milling method for enhanced sorption of $\mathrm{CO}_{2}$ and reactive red. Chem Eng J 368:564-572. https://doi.org/10. 1016/j.cej.2019.02.165

Xu L, Wu C, Liu P et al (2020) Peroxymonosulfate activation by nitrogen-doped biochar from sawdust for the efficient degradation of organic pollutants. Chem Eng J. https://doi.org/10.1016/j.cej. 2020.124065

Yagub MT, Sen TK, Afroze S, Ang HM (2014) Dye and its removal from aqueous solution by adsorption: a review. Adv Coll Interface Sci 209:172-184. https://doi.org/10.1016/j.cis.2014.04.002

Yang GX, Jiang H (2014) Amino modification of biochar for enhanced adsorption of copper ions from synthetic wastewater. Water Res 48:396-405. https://doi.org/10.1016/j.watres.2013.09.050

Yang F, Sun L, Xie W et al (2017) Nitrogen-functionalization biochars derived from wheat straws via molten salt synthesis: an efficient adsorbent for atrazine removal. Sci Total Environ 607-608:13911399. https://doi.org/10.1016/j.scitotenv.2017.07.020

Yin W, Zhang W, Zhao C, Xu J (2019) Evaluation of removal efficiency of $\mathrm{Ni}(\mathrm{II})$ and 2,4-DCP using in situ nitrogen-doped biochar modified with aquatic animal waste. ACS Omega 4:19366-19374. https://doi.org/10.1021/acsomega.9b02769

Yu W, Lian F, Cui G, Liu Z (2018) N-doping effectively enhances the adsorption capacity of biochar for heavy metal ions from aqueous solution. Chemosphere 193:8-16. https://doi.org/10.1016/j. chemosphere.2017.10.134

Yu J, Tang L, Pang Y et al (2019) Magnetic nitrogen-doped sludgederived biochar catalysts for persulfate activation: internal electron transfer mechanism. Chem Eng J 364:146-159. https://doi org/10.1016/j.cej.2019.01.163

Yuan S, Tan Z, Huang Q (2018a) Migration and transformation mechanism of nitrogen in the biomass-biochar-plant transport process. Renew Sustain Energy Rev 85:1-13. https://doi.org/10.1016/j. rser.2018.01.008

Yuan X, An N, Zhu Z et al (2018b) Hierarchically porous nitrogendoped carbon materials as efficient adsorbents for removal of heavy metal ions. Process Saf Environ Prot 119:320-329. https:// doi.org/10.1016/j.psep.2018.08.012

Yue G, Meng K, Liu Q (2015) One-step synthesis of N-doped carbon and its application as a cost-efficient catalyst for the oxygen reduction reaction in microbial fuel cells. ChemPlusChem 80:1133-1138. https://doi.org/10.1002/cplu.201500057

Zaeni JRJ, Lim JW, Wang Z et al (2020) In situ nitrogen functionalization of biochar via one-pot synthesis for catalytic peroxymonosulfate activation: characteristics and performance studies. Sep Purif Technol. https://doi.org/10.1016/j.seppur.2020.116702

Zhang L, Xia Z (2011) Mechanisms of oxygen reduction reaction on nitrogen-doped graphene for fuel cells. J Phys Chem C 115:11170-11176. https://doi.org/10.1021/jp201991j

Zhang X, Zhang S, Yang H et al (2014) Nitrogen enriched biochar modified by high temperature $\mathrm{CO}_{2}$-ammonia treatment: characterization and adsorption of $\mathrm{CO}_{2}$. Chem Eng J 257:20-27. https:// doi.org/10.1016/j.cej.2014.07.024

Zhang X, Zhang S, Yang H et al (2015) Effects of hydrofluoric acid pre-deashing of rice husk on physicochemical properties and $\mathrm{CO}_{2}$ adsorption performance of nitrogen-enriched biochar. Energy 91:903-910. https://doi.org/10.1016/j.energy.2015.08.028

Zhang ZB, Cao XH, Liang P, Liu YH (2013) Adsorption of uranium from aqueous solution using biochar produced by hydrothermal carbonization. J Radioanal Nucl Chem 295(2):1201-1208

Zhang X, Wu J, Yang H et al (2016) Preparation of nitrogen-doped microporous modified biochar by high temperature $\mathrm{CO}_{2}-\mathrm{NH}_{3}$ treatment for $\mathrm{CO}_{2}$ adsorption: effects of temperature. RSC Adv 6:98157-98166. https://doi.org/10.1039/c6ra23748g

Zhang X, Zhang S, Yang H et al (2017) Generalized two-dimensional correlation infrared spectroscopy to reveal mechanisms of 
$\mathrm{CO}_{2}$ capture in nitrogen enriched biochar. Proc Combust Inst 36:3933-3940. https://doi.org/10.1016/j.proci.2016.06.062

Zhang A, Li X, Xing J, Xu G (2020a) Adsorption of potentially toxic elements in water by modified biochar: a review. J Environ Chem Eng. https://doi.org/10.1016/j.jece.2020.104196

Zhang Y, Deng L, Hu H et al (2020b) Pomelo peel-derived, N-doped biochar microspheres as an efficient and durable metal-free ORR catalyst in microbial fuel cells. Sustain Energy Fuels 4:16421653. https://doi.org/10.1039/c9se00834a

Zhao Y, Zhang X, He Y et al (2017) Biomass derived nitrogen-doped highly porous carbon material with a hierarchical porous structure for high-performance lithium/sulfur batteries. Materials. https://doi.org/10.3390/ma10101158

Zheng X, Zhou Y, Liu X et al (2020) Enhanced adsorption capacity of $\mathrm{MgO} / \mathrm{N}$-doped active carbon derived from sugarcane bagasse. Bioresour Technol 297:122413. https://doi.org/10.1016/j.biort ech.2019.122413

Zhong K, Li M, Yang Y et al (2019) Nitrogen-doped biochar derived from watermelon rind as oxygen reduction catalyst in air cathode microbial fuel cells. Appl Energy 242:516-525
Zhong Q, Lin Q, Huang R et al (2020) Oxidative degradation of tetracycline using persulfate activated by $\mathrm{N}$ and $\mathrm{Cu}$ codoped biochar. Chem Eng J 380:122608

Zhu R, Chen Q, Zhou Q et al (2016) Adsorbents based on montmorillonite for contaminant removal from water: a review. Appl Clay Sci 123:239-258. https://doi.org/10.1016/j.clay.2015.12.024

Zhu S, Huang X, Ma F et al (2018) Catalytic removal of aqueous contaminants on $\mathrm{N}$-doped graphitic biochars: inherent roles of adsorption and nonradical mechanisms. Environ Sci Technol 52:8649-8658. https://doi.org/10.1021/acs.est.8b01817

Zhu K, Bin Q, Shen Y et al (2020a) In-situ formed N-doped bamboolike carbon nanotubes encapsulated with Fe nanoparticles supported by biochar as highly efficient catalyst for activation of persulfate (PS) toward degradation of organic pollutants. Chem Eng J 402:126090. https://doi.org/10.1016/j.cej.2020.126090

Zhu S, Huang X, Yang X et al (2020b) Enhanced transformation of $\mathrm{Cr}(\mathrm{VI})$ by heterocyclic-N within nitrogen-doped biochar: impact of surface modulatory persistent free radicals (PFRs). Environ Sci Technol 54:8123-8132. https://doi.org/10.1021/acs.est.0c027 13 